\title{
The World in 2050
}

Will the shift in global economic power continue?

February 2015 


\section{Contents}

1. Summary: The world in $2050 \quad 1$

1.1. Highlights 1

1.2. Key findings: GDP projections to $2050 \quad 1$

1.3. Implications for business strategy 4

2. Introduction 6

2.1. Background to the 'World in 2050' reports 6

2.2. Our modelling approach 6

2.3. What has changed since the January 2013 update? 7

2.4. Structure of this report $\quad 7$

3. Key results 8

3.1. $\quad$ Relative size of the economies 8

3.2. Projected real GDP growth 17

3.3. Relative income levels 21

3.4. Scenario analysis 22

4. Institutional challenges and business implications 25

4.1. Escaping the middle income trap - the critical role of institutions 25

4.2. Implications for business strategy 30

\section{Appendices}

Appendix A: Drivers of growth $\quad 35$

Appendix B: Additional projections for GDP at market exchange rates 40

Authors, contacts and services 


\section{Summary: The world in 2050}

\subsection{Highlights}

In our latest World in 2050 report we present economic growth projections for 32 of the largest economies in the world, accounting for around $84 \%$ of global GDP.

We project the world economy to grow at an average of just over $3 \%$ per annum in the period $2014-50$, doubling in size by 2037 and nearly tripling by 2050 .

But we expect a slowdown in global growth after 2020, as the rate of expansion in China and some other major emerging economies moderates to a more sustainable long-term rate, and as working age population growth slows in many large economies.

The global economic power shift ${ }^{1}$ away from the established advanced economies in North America, Western Europe and Japan will continue over the next 35 years. China has already overtaken the US in 2014 to become the largest economy in purchasing power parity $\left(\mathrm{PPP}^{2}\right)$ terms. In market exchange rate (MER) terms, we project China to overtake the US in 2028 despite its projected growth slowdown.

India has the potential to become the second largest economy in the world by 2050 in PPP terms (third in MER terms), although this requires a sustained programme of structural reforms 3 .

We project new emerging economies like Mexico and Indonesia to be larger than the UK and France by 2030 (in PPP terms) while Turkey could become larger than Italy. Nigeria and Vietnam could be the fast growing large economies over the period to 2050.

Colombia, Poland and Malaysia all possess great potential for sustainable long-term growth in the coming decades according to our country experts.

At the same time, recent experience has re-emphasised that relatively rapid growth is not guaranteed for emerging economies, as indicated by recent problems in Russia and Brazil, for example. It requires sustained and effective investment in infrastructure and improving political, economic, legal and social institutions. It also requires remaining open to the free flow of technology, ideas and talented people that are key drivers of economic catch-up growth.

We think that overdependence on natural resources could also impede long term growth in some countries (e.g. Russia, Nigeria and Saudi Arabia) unless they can diversify their economies.

\subsection{Key findings: GDP projections to 2050}

This report updates our long-term global economic growth projections 4 , which were last published in January 2013. These are based on a model that takes account of projected trends in demographics, capital investment, education levels and technological progress. We have updated both the base year data (from 2011 to 2014) and

\footnotetext{
${ }^{1}$ This is one of the five long-term megatrends that have been the focus of much recent PwC research, and is closely related to other key global trends related to demographic and social change, rapid urbanisation, technological breakthroughs, and resource scarcity and climate change. For more details of this megatrends research, please see our website here: http://www.pwc.co.uk/issues/megatrends/index.jhtml ${ }_{2}^{2}$ PPP estimates adjust for price level differences across countries (see Appendix A for more details). They therefore provide a better measure of the volume of goods and services produced than GDP at current market exchange rates.

3 As discussed further in the recent PwC report on the future of India 'The Winning Leap': http://www.pwc.in/en_in/in/assets/pdfs/futureof-india/future-of-india-the-winning-leap.pdf. Potentially, Indian GDP could reach $\$ 10$ trillion by 2035 if the right policies are pursued.

4 Our projections indicate potential growth if broadly growth-friendly policies are pursued by governments in these countries and if there are no major global catastrophes (e.g. global nuclear war, asteroid collision, long-lasting global pandemic). They are subject to many uncertainties as discussed in the scenario analysis in Section 3.4 of the report.
} 
future assumptions on the key drivers of growth, as well as expanding the coverage of the model from 24 to 32 countries (now accounting for around $84 \%$ of total world GDP at PPP exchange rates).

Figure 1 below shows the estimated average real GDP growth rates for the 32 economies covered in this study over the period to 2050. Newly emerging economies such as Nigeria and Vietnam could grow at $5 \%$ or more per annum on average over this period, whilst the growth of established emerging economies such as China may moderate to around 3-4\%. Advanced economies are projected to grow at around $1.5-2.5 \%$ per annum in the long run, with variations reflecting different working age population growth to a significant degree.

Figure 1: Breakdown of components of average annual real GDP growth (2014 - 2050)

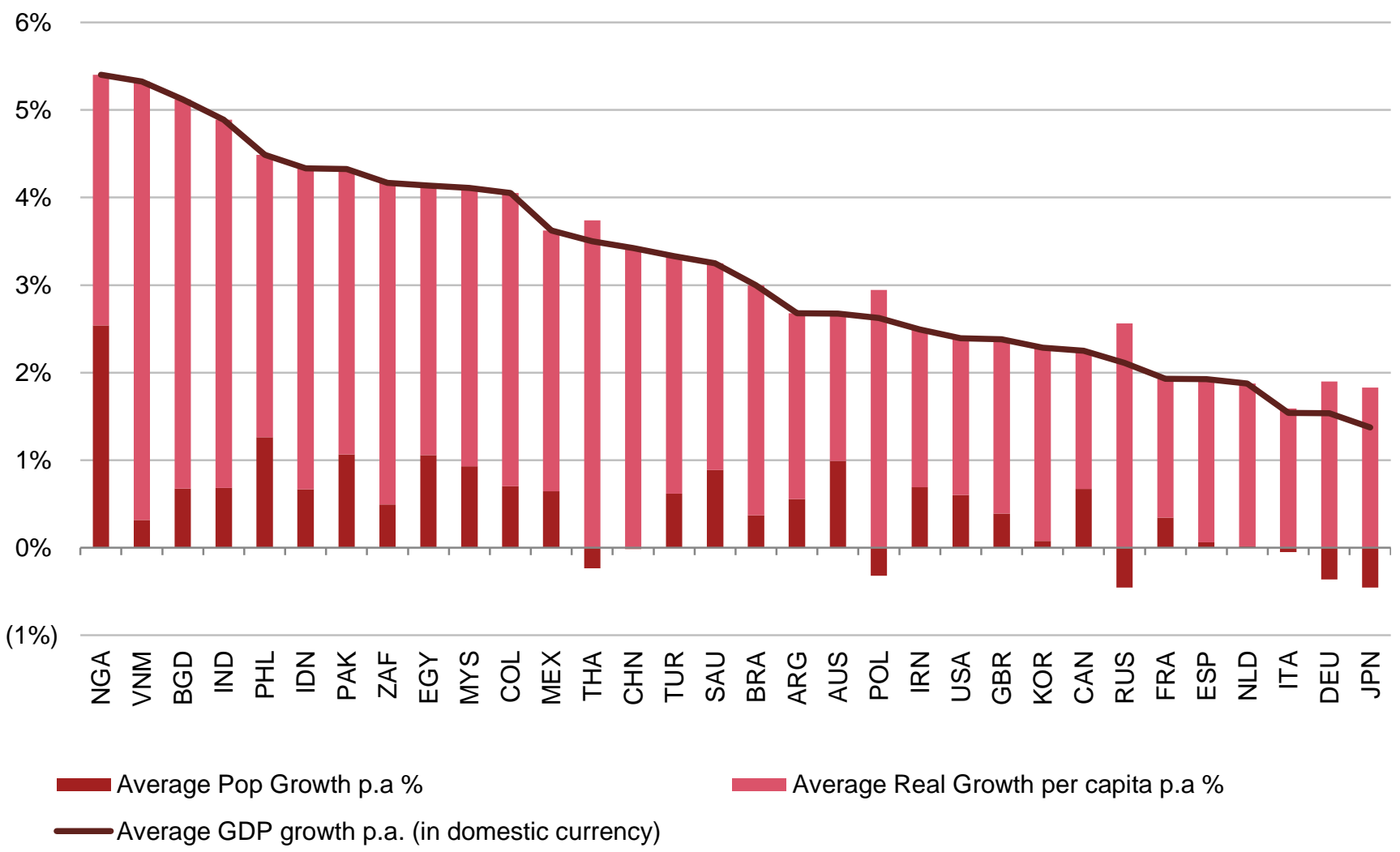

Source: PwC analysis

The changing league table of world GDP in PPP terms is shown in Table 1. China is already the world's biggest economy in PPP terms, and we project that India could have the potential to just overtake the US as the world's second largest economy by 2050 in PPP terms (although the projected difference is small relative to the margin of uncertainty around any such projections).

We project that the gap between the three biggest economies (i.e. China, India and the US) and the rest of the world will widen over the next few decades. In 2014, the third biggest economy in PPP terms (India) is around $50 \%$ larger than the fourth biggest economy (Japan). In 2050, the third biggest economy in PPP terms (the US) is projected to be approximately $240 \%$ larger than the fourth biggest economy (Indonesia).

The rise of Indonesia and Nigeria through the world rankings throughout the period to 2050 is very striking: Indonesia rises from 9th in 2014 to 4 th in 2050, and Nigeria rises from 20th in 2014 to 9 th in 2050.

However, average income per capita (i.e. GDP per capita) will still be significantly higher in the advanced economies than the emerging economies in 2050. The current gap in income per capita between developing and developed countries is just too large to bridge fully over this period. 
Table 1: GDP at PPP rankings

\begin{tabular}{|c|c|c|c|c|c|c|}
\hline \multirow[b]{2}{*}{$\begin{array}{l}\text { PPP } \\
\text { rank }\end{array}$} & \multicolumn{2}{|c|}{2014} & \multicolumn{2}{|c|}{2030} & \multicolumn{2}{|c|}{2050} \\
\hline & Country & $\begin{array}{l}\text { GDP at PPP } \\
\text { (2014 US\$bn) }\end{array}$ & Country & $\begin{array}{c}\text { Projected GDP } \\
\text { at PPP } \\
\text { (2014 US\$bn) }\end{array}$ & Country & $\begin{array}{c}\text { Projected GDP } \\
\text { at PPP } \\
\text { (2014 US\$bn) }\end{array}$ \\
\hline 1 & China & 17,632 & China & 36,112 & China & 61,079 \\
\hline 2 & United States & 17,416 & United States & 25,451 & India & 42,205 \\
\hline 3 & India & 7,277 & India & 17,138 & United States & 41,384 \\
\hline 4 & Japan & 4,788 & Japan & 6,006 & Indonesia & 12,210 \\
\hline 5 & Germany & 3,621 & Indonesia & 5,486 & Brazil & 9,164 \\
\hline 6 & Russia & 3,559 & Brazil & 4,996 & Mexico & 8,014 \\
\hline 7 & Brazil & 3,073 & Russia & 4,854 & Japan & 7,914 \\
\hline 8 & France & 2,587 & Germany & 4,590 & Russia & 7,575 \\
\hline 9 & Indonesia & 2,554 & Mexico & 3,985 & Nigeria & 7,345 \\
\hline 10 & United Kingdom & 2,435 & United Kingdom & 3,586 & Germany & 6,338 \\
\hline 11 & Mexico & 2,143 & France & 3,418 & United Kingdom & 5,744 \\
\hline 12 & Italy & 2,066 & Saudi Arabia & 3,212 & Saudi Arabia & 5,488 \\
\hline 13 & South Korea & 1,790 & South Korea & 2,818 & France & 5,207 \\
\hline 14 & Saudi Arabia & 1,652 & Turkey & 2,714 & Turkey & 5,102 \\
\hline 15 & Canada & 1,579 & Italy & 2,591 & Pakistan & 4,253 \\
\hline 16 & Spain & 1,534 & Nigeria & 2,566 & Egypt & 4,239 \\
\hline 17 & Turkey & 1,512 & Canada & 2,219 & South Korea & 4,142 \\
\hline 18 & Iran & 1,284 & Spain & 2,175 & Italy & 3,617 \\
\hline 19 & Australia & 1,100 & Iran & 1,914 & Canada & 3,583 \\
\hline 20 & Nigeria & 1,058 & Egypt & 1,854 & Philippines & 3,516 \\
\hline 21 & Thailand & 990 & Thailand & 1,847 & Thailand & 3,510 \\
\hline 22 & Egypt & 945 & Pakistan & 1,832 & Vietnam & 3,430 \\
\hline 23 & Poland & 941 & Australia & 1,707 & Bangladesh & 3,367 \\
\hline 24 & Argentina & 927 & Malaysia & 1,554 & Malaysia & 3,327 \\
\hline 25 & Pakistan & 884 & Poland & 1,515 & Iran & 3,224 \\
\hline 26 & Netherlands & 798 & Philippines & 1,508 & Spain & 3,099 \\
\hline 27 & Malaysia & 747 & Argentina & 1,362 & South Africa & 3,026 \\
\hline 28 & Philippines & 695 & Vietnam & 1,313 & Australia & 2,903 \\
\hline 29 & South Africa & 683 & Bangladesh & 1,291 & Colombia & 2,785 \\
\hline 30 & Colombia & 642 & Colombia & 1,255 & Argentina & 2,455 \\
\hline 31 & Bangladesh & 536 & South Africa & 1,249 & Poland & 2,422 \\
\hline 32 & Vietnam & 509 & Netherlands & 1,066 & Netherlands & 1,581 \\
\hline
\end{tabular}

Source: IMF WEO database (October 2014) for 2014 estimates, PwC projections for 2030 and 2050 


\section{The model projections highlight a likely moderation in growth rates after 2020}

Figure 2 shows projected average annual real GDP growth rates for the BRICs, the US, the UK, the EU and the world over the period to 2020 and in the following three decades. Our model suggests that growth in emerging economies, particularly China but also to a lesser degree India, could moderate after 2020 as they mature. In general, as is consistent with the findings of recent academic research by Larry Summers and Lant Pritchett 5 , our projections shows a tendency for growth rates to 'regress to the mean' in the long run. Brazil and Russia show a slightly different pattern since short-term problems give them scope to improve in the 2020s, but they too see their growth rates revert back towards the advanced economy norm of around $2 \%$ in the longer run.

Figure 2: Projected growth profiles for major economies - Regression to the mean

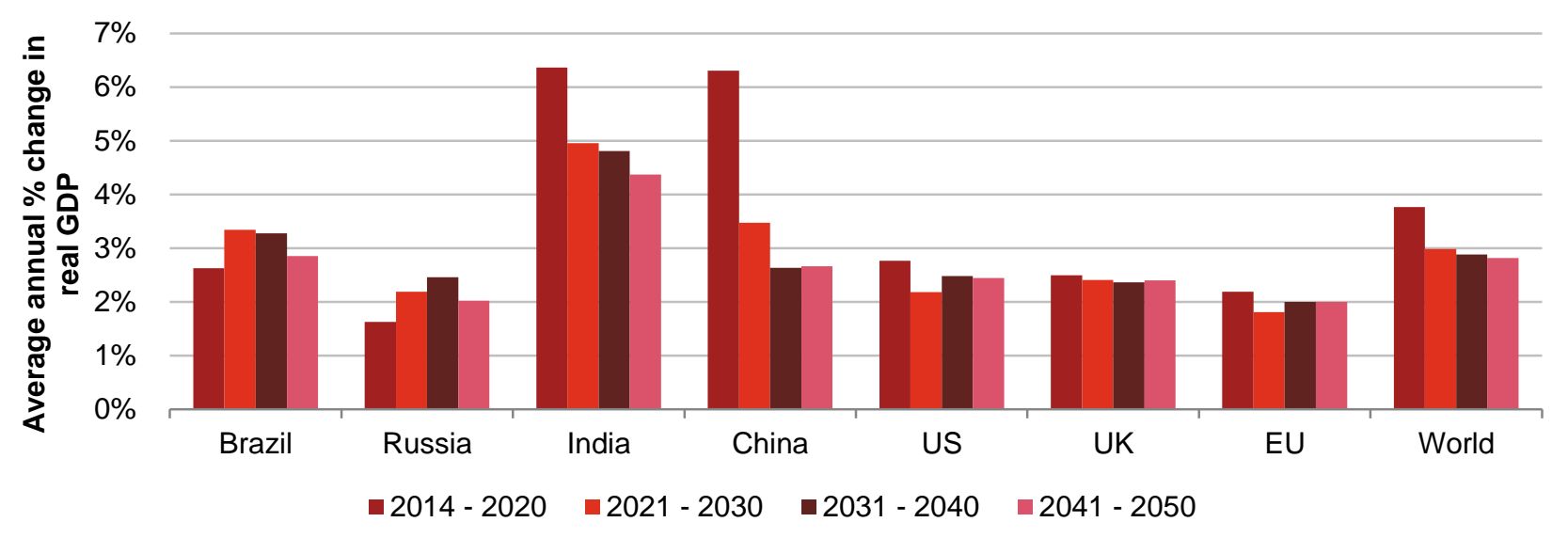

Source: PwC analysis

Of course, any such long-term growth projections are subject to many uncertainties. In Section 3.4 of the report, for example, we consider an alternative downside scenario where global growth could average around 0.7\% per annum lower, leading to global GDP by 2050 being around $22 \%$ lower than in our main projections. This reflects less favourable assumptions on technological progress, investment levels and catch-up rates for emerging economies, although of course there could also be upside possibilities that would push global growth above our baseline projections.

\subsection{Implications for business strategy}

Our analysis has a number of high level messages for businesses considering how to develop their global strategies, although all of these would need careful tailoring to individual circumstances. Our Growth Markets Centre has also developed a detailed toolkit to help companies address these and related strategic issues ${ }^{6}$.

First, it will be difficult to sustain the growth rates of the 2000 to 2012 period in the E7 and other major emerging markets, given the combination of economic bottlenecks and institutional deficiencies. This is backed up by the detailed analysis in this report. Managers need to understand the political, legal and regulatory risks and have procedures in place to avoid or at least mitigate them as they arise. They also need to understand the dynamics of emerging consumer markets that are becoming increasingly mature, sophisticated and digitally savvy.

Second, emerging markets vary greatly in their institutional strengths and weaknesses and need to be assessed in a nuanced way. There could also be major differences in institutional strengths between industry sectors within countries. Deep local knowledge that is updated in real time is critical here to manage businesses successfully in an emerging market environment. Having the right local partners to navigate you through local

\footnotetext{
5 L. Pritchett and L.H. Summers, 'Asiaphoria Meets Regression to the Mean', NBER, October 2014: http://www.nber.org/papers/w20573 ${ }^{6}$ As discussed further in Section 4.2 below and on our Growth Markets Centre website at: http://www.pwc.com/gx/en/growth-marketscentre/index.jhtml
} 
political, legal and regulatory systems is also critical7. Identifying and promoting local talent who understand local business and social cultures better than any outsider will also be an increasing source of comparative advantage.

Third, for larger Western companies making strategic investments in emerging markets, part of their contribution could be to try to improve the local institutional framework. This could involve offering appropriate technical assistance and advice to local governments in areas like corporate governance, fiscal policy and intellectual property rights protection. It could also involve investing in social and economic infrastructure (e.g. schools, roads, railways, power and water networks) where these are critical to a company's longer term success in a region.

Finally, don't forget existing core markets in North America and Europe. These will remain very significant players in the global economy for decades to come. Our analysis shows that their average income levels will remain much higher than in even the best-performing emerging markets for the foreseeable future. Advanced economies will also, generally speaking, still be easier and lower risk places to do business given their political and institutional strengths, even though we project their growth rates to be relatively slow.

In short, while emerging markets have considerable growth potential, they can also be an institutional minefield - both managers and investors need to tread carefully. Global strategies need to strike the right balance between mature, lower risk advanced economies and faster-growing but generally higher risk emerging markets. The correct balance will vary from company to company, but our Growth Markets Strategy toolkit can help guide the way.

\footnotetext{
${ }_{7}$ As discussed in more detail in a recent PwC Growth Markets Centre report 'Presence to Prosperity' : http://www.pwc.com/gx/en/growthmarkets-centre/presence-to-profitability.jhtml
} 


\section{Introduction}

\subsection{Background to the 'World in 2050' reports}

We published the first edition of our 'World in 2050' report in March 2006, which set out projections for potential growth in GDP in 17 leading economies over the period to 2050. These countries were:

- the G7 (the US, Japan, Germany, the UK, France, Italy and Canada), plus Australia, South Korea and Spain among the current advanced economies; and

- the seven largest emerging market economies, which we refer to collectively as the $\mathbf{E}_{7}$ (China, India, Brazil, Russia, Indonesia, Mexico and Turkey).

These projections were updated in March 2008, January 2011 and January 2013, expanding the country coverage by adding:

- Argentina, South Africa and Saudi Arabia so that all of the G20 economies were covered;

- Vietnam and Nigeria as potential fast-growing frontier economies; and

- Poland (as the largest economy in Central and Eastern Europe except Russia) and Malaysia (as a fastgrowing medium-sized economy within the Asia-Pacific region).

Two years after the last update in January 2013, we are now revisiting our 'World in 2050' GDP projections, and extending the country coverage to include eight additional relatively large economies: Bangladesh, Colombia, Egypt, Iran, the Netherlands, Pakistan, Philippines and Thailand.

Our World in 2050 model therefore now covers a total of 32 countries, which currently account for around $84 \%$ of world GDP (up from around 80\% for the 24 economies in our 2013 report).

Our analysis suggests that this group of 32 countries should have a high probability of including at least the largest 25 economies in the world looking ahead to the middle of this century. We cannot say, however, that they will necessarily be the largest 32 economies bearing in mind the considerable uncertainties that come with any such long-term projections. There could be some other fast-rising economies that overtake some of this group of 32 by 2050.

\subsection{Our modelling approach}

We use the International Monetary Fund's World Economic Outlook (October 2014) estimates for GDP in 2014 as the starting point for our projections. We then use our long-term economic model to estimate trend growth rates to 2050. These longer term trend growth estimates, which abstract from shorter term cyclical trends, are driven by the following key factors:

- Growth in the labour force of working age (based on the latest UN population projections);

- Increases in human capital, proxied here by average education levels across the adult population;

- Growth in the physical capital stock, which is driven by capital investment net of depreciation; and

- Total factor productivity growth, which is driven by technological progress and catching up by lower income countries with richer ones by making use of their technologies and processes.

Emerging economies have stronger potential growth than the current advanced economies on most of these measures, although it should be stressed that this assumes they continue to follow broadly growth-friendly policies. In this sense, the projections are of potential future GDP if such policies are followed, rather than predictions of what will actually happen, bearing in mind that not all of these countries may be able to sustain such policies in the long-run in practice. 
There are, of course, also many other uncertainties surrounding these long-term growth projections, so more attention should be paid to the broad trends indicated rather than the precise numbers quoted in this report. The broad conclusions reached on the shift in global economic power from the G7 to the E7 emerging economies should, however, be robust to these uncertainties, provided that there are no catastrophic shocks (e.g. global nuclear war, asteroid collisions, extreme global climate change etc.) that derail the overall global economic development process.

More details regarding our modelling approach and key assumptions can be found in Appendix A at the end of this report.

\subsection{What has changed since the January 2013 update?}

There are three main changes which we made to the analysis since our last published update in January 2013:

1. We have updated the data on GDP in PPP terms with the new set of data released by the World Bank/IMF/UN/OECD International Comparison Program (ICP) in 2014. Methodological changes have been made in the calculation of the PPP data, which resulted in some significant changes in the rankings of economies in terms of \% of world GDP8 and the estimated starting point for levels of GDP at PPPs in our model.

2. We updated all historical data in the model so that the base year is now 2014rather than 2011. Our detailed assumptions on future trends in key input variables were also revised to reflect actual trends over the past two years and the latest thinking of $\mathrm{PwC}$ and external experts (e.g. using the latest available UN population projections).

3. As noted above, we added eight countries (Bangladesh, Colombia, Egypt, Iran, the Netherlands, Pakistan, Philippines and Thailand) to the analysis.

The model results presented in this report are based on 2014 GDP estimates taken from the October 2014 edition of the IMF's WEO publication. These 2014 GDP estimates will be revised over time, which is one reason why we would stress that the focus should be on the broad trends in the GDP projections and rankings, rather than the precise numbers shown in this report, which are inevitably subject to many uncertainties.

\subsection{Structure of this report}

The rest of the report is structured as follows:

- Section 3 summarises the key results of the analysis in terms of projected GDP levels, growth rates and average income trends to 2050. It also includes analysis of alternative scenarios to capture some of the uncertainties around our main scenario projections.

- Section 4 discusses the institutional challenges that many emerging economies face if they are to realise their growth potential and escape the 'middle income trap'. It also discusses the implications of our results for business strategy in both emerging and advanced economies.

- Appendix A provides further details of our methodological approach, including the assumptions made on the key drivers of growth in the model; and

- Appendix B includes some additional results based on GDP at MERs, whereas Section 3 focuses more on the results for GDP at PPPs.

The report also includes boxes giving views from four PwC country experts (on Poland, Colombia, Nigeria and Malaysia) and three external members of PwC's Chief Economists' roundtable (Rebecca Harding, Richard Woolhouse and Adam Smith). These expert perspectives add extra detail and insight to the GDP projections that form the core of the report.

\footnotetext{
${ }^{8}$ For example, the new ICP data 'reveal that PPP-based consumption and GDP expenditures in most poor economies are larger than previously thought, based on analysis of the ICP 2005 results.'
} 


\section{Key results}

\subsection{Relative size of the economies}

\subsubsection{G7versus E7}

In this section, we look at how the relative sizes of different economies are projected to change over time. Figure 3 below shows that, in 2014, the E7 countries have already overtaken the G7 countries in terms of total GDP at PPP exchange rates. This is a measure of the volume of goods and services produced, after correcting for price level variations across countries. Based on total GDP at MERs, however, the G7 economies are still around 80\% larger than the E7 economies. This reflects the much lower average price levels in emerging than advanced economies at current market exchange rates.

Looking forward, our base case projections suggest that the GDP of the E7 countries will be around twice as high as that for the G7 countries by 2050 in PPP terms, and more than 50\% higher in MER terms.

Figure 3: Relative size of $\mathrm{G}_{7}$ and $\mathrm{E}_{7}$ economies, 2014 and 2050

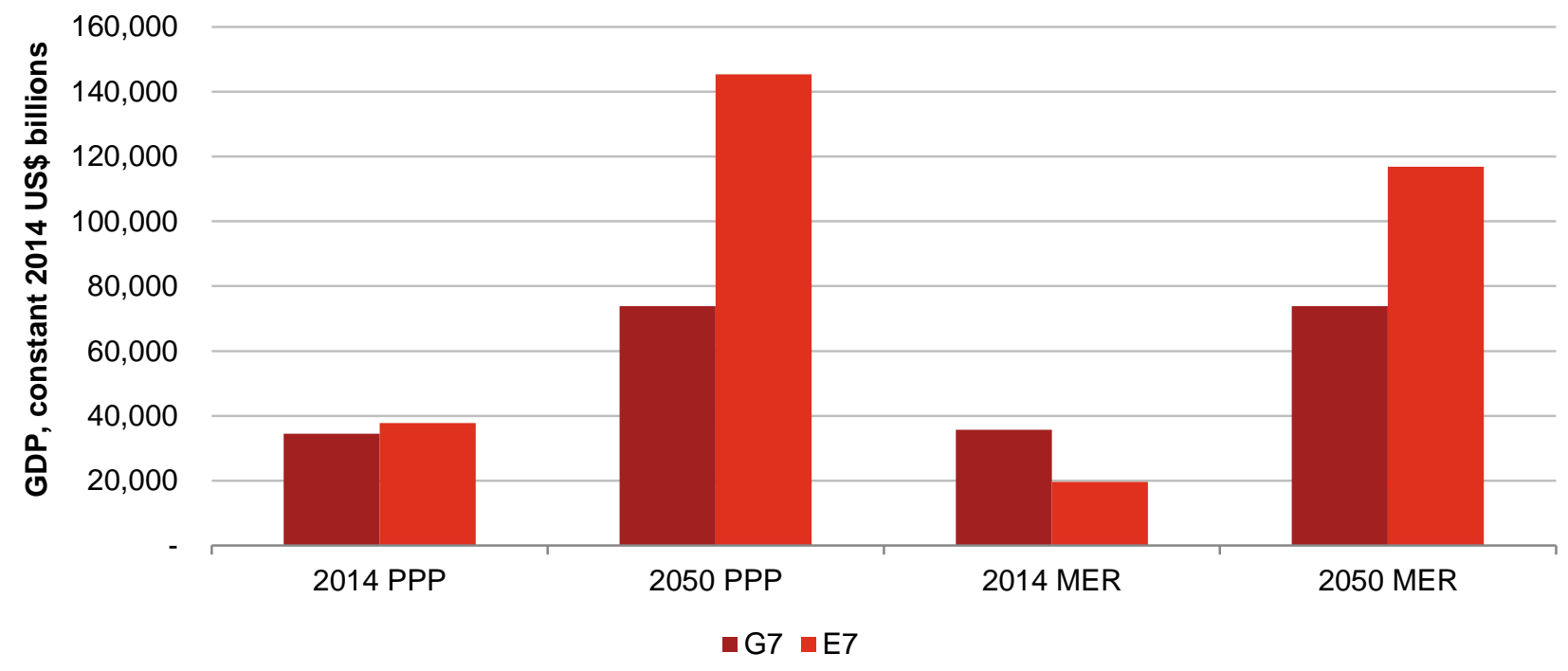

Source: IMF for 2014 estimates, PwC projections for 2050

Figure 4 belowshows the growth paths of the E7 and G7 countries in PPP terms. Again, it shows that the E7 economies have already overtaken the G7 economies as of 2014. This is earlier than the 2017 'crossover date' in our previous model projections in the January 2013 version of this report, which can mainly be attributed to new data on GDP in PPP terms released during 2014 by the World Bank/IMF/UN/OECD's International Comparison Program (ICP). Methodological improvements have been made that suggest lower relative price levels in some major emerging economies relative to the advanced economies. National GDP revisions have also played a smaller part in this shift. 
Figure 4: E7 and G7 growth paths in PPP terms

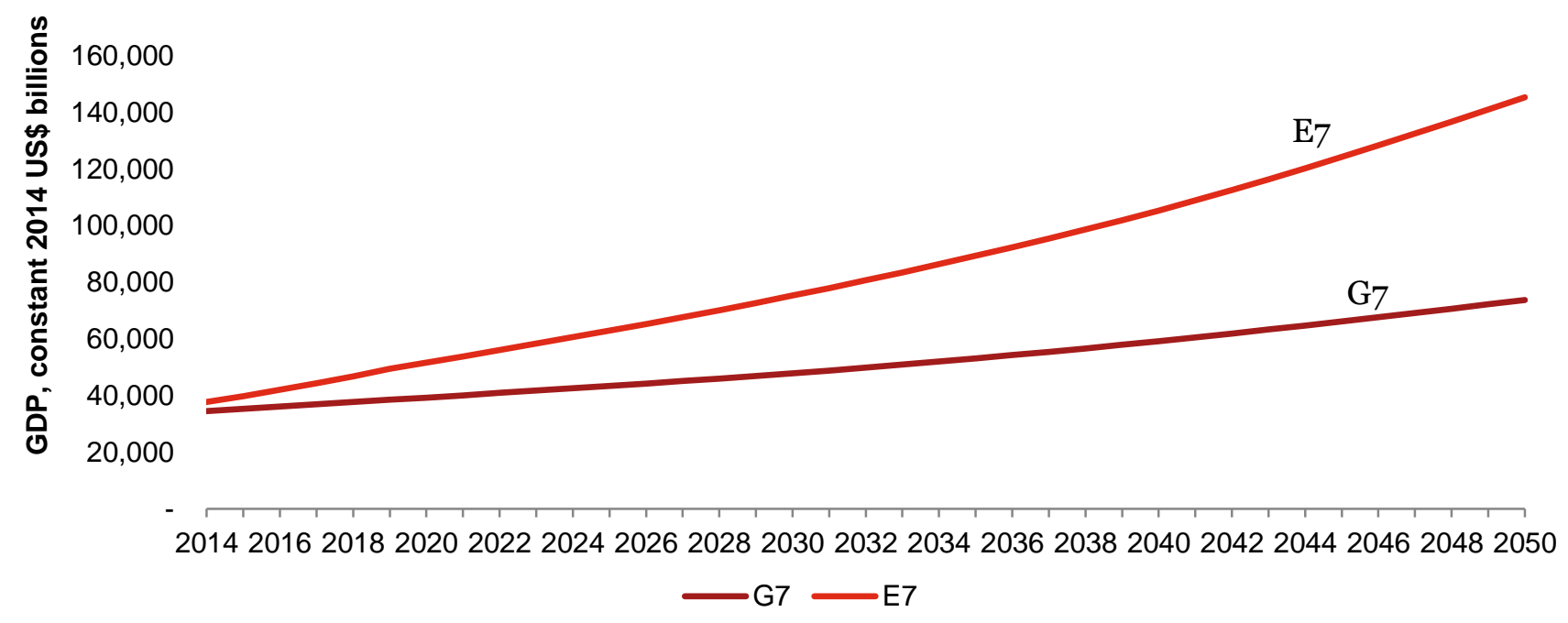

Source: PwC analysis

It is expected that the $\mathrm{E} 7$ economies will continue to be the driving force of the world economy in $2014-2050$. Our model suggests that the E7 could grow at an average rate of 3.8\% p.a. during the period 2014-2050, whilst the G7 could grow at an average rate of just $2.1 \%$ p.a. over the same time period.

Figure 5 shows the growth paths of the E7 and G7 countries in MER terms. This shows that the E7 economies were still around $45 \%$ smaller than the $\mathrm{G} 7$ countries in terms of the value of their output at current exchange rates. Our model projections suggest, however, that the $\mathrm{E}_{7}$ countries could overtake the G7 countries in around 2030 in MER terms.

Figure 5: E7 and G7 growth paths in MER terms

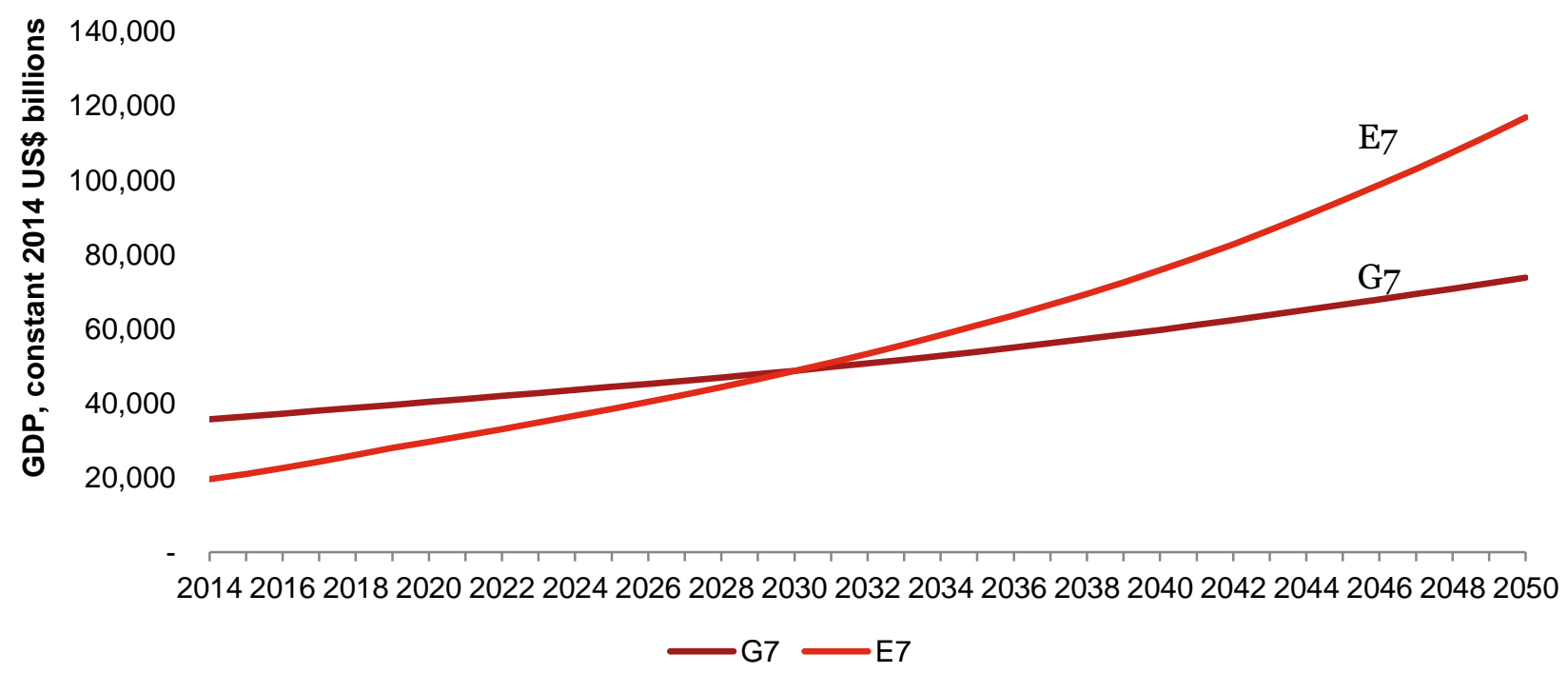

Source: PwC analysis 
As noted above, the difference between the PPP and MER estimates reflects the fact that price levels in the E7 economies are, on average, still well below $\mathrm{G} 7$ levels when compared using current market exchange rates. This is a commonly observed phenomenon for many emerging economies. However, past experience with fastgrowing countries such as Japan in the 1960s-1980s or South Korea in the 1970s-1990s suggests that market exchange rates tend to converge gradually with PPP rates as economic development continues. This could occur through nominal exchange rate appreciation or relatively high price inflation in the emerging economies, but in either case the result is likely to be long-run real currency appreciation for these economies. We have incorporated this effect into our model through an econometric equation estimated based on past data. This results in a gradual long term convergence with PPP rates that forms the basis for our projections of GDP in MER terms as shown, for example, in Figure 5. However, these real exchange rate projections are highly uncertain in practice, so we put more weight on the PPP results in the rest of this section, with further details on the MER results being included in Appendix B.

\subsubsection{Projected shifts in global economic power by 2050}

Much of the growth taking place within the E7 stems from China and India. As shown in Figure 6, China, India and the US are likely to be by far the three largest economies in the world by 2050. Interestingly, our model projections indicate that there could still be a relatively large gap between India's GDP in PPP and MER terms by 2050, suggesting that India's price level could still be below advanced economy levels by then, reflecting its still relatively low average income levels at that date (as discussed further in Section 3.3 below).

Figure 6: Relative GDP at MERs and PPPs in 2050 (\% of US levels)

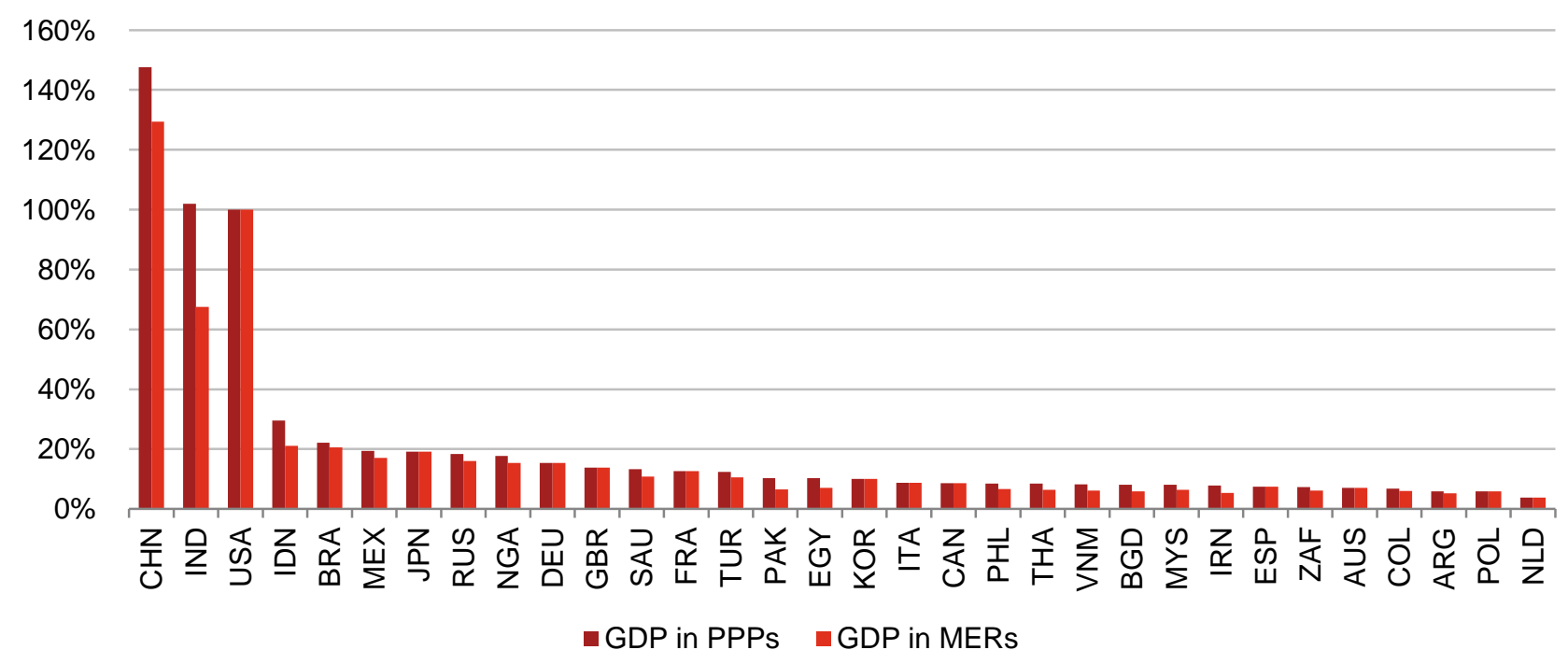

Source: PwC analysis

According to the latest economic data, China has already overtaken the US in PPP terms. Our model suggests that China could overtake the US before 2030 in MER terms (see Figure 7 below). Again, as mentioned above, this is subject to our assumptions on the degree of convergence of China's market exchange rate with the PPP exchange rate, which are plausible but nonetheless subject to significant uncertainty. 
Figure 7: Projected GDP growth paths of China and the US

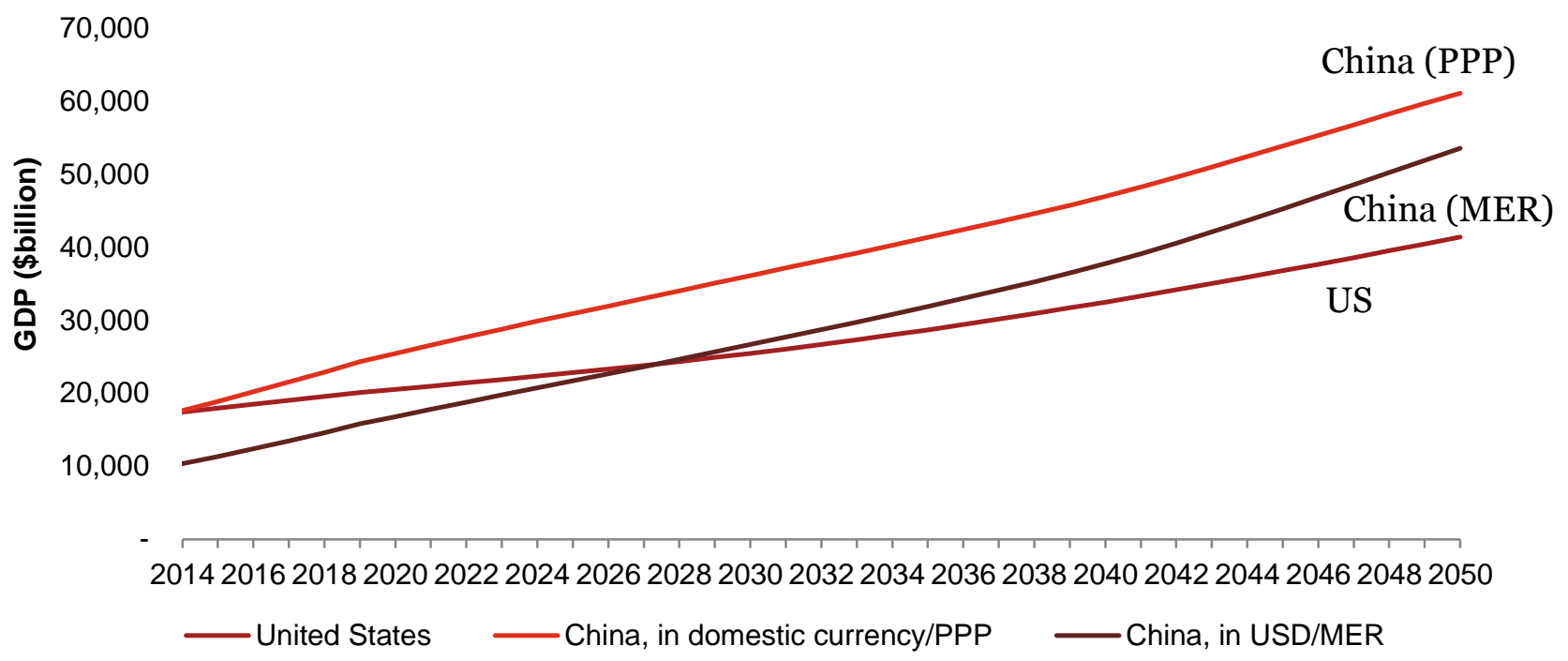

Source: PwC analysis (based on IMF estimates for 2014)

It is expected that the shift in economic power that we have seen in recent decades will continue. Our model projects that China's share of world GDP in PPP terms will increase from $16.5 \%$ in 2014 to a peak of around $20 \%$ in 2030 before declining to around $19.5 \%$ in 2050. India's share of world GDP in PPP terms could increase steadily from just under $7 \%$ in 2014 to around $13.5 \%$ in 2050. Our model suggests that India could overtake the EU and the US in terms of share of world GDP in PPP terms by 2044 and 2049 respectively. Given the rise of India and China, our model suggests that the US and the EU's share of world GDP in PPP terms will face a steady decline from around $33 \%$ in 2014 to only around $25 \%$ by 2050. This shift of global economic power to Asia may occur somewhat more quickly or slowly than this, of course, but the general direction of change and the historic nature of this shift are clear. In many ways, it is a return to the pre-Industrial Revolution era when China and India dominated world GDP in large due to their great populations, and relatively efficient agricultural sectors at that time.

Figure 8: Key economies' share of world GDP in PPP terms

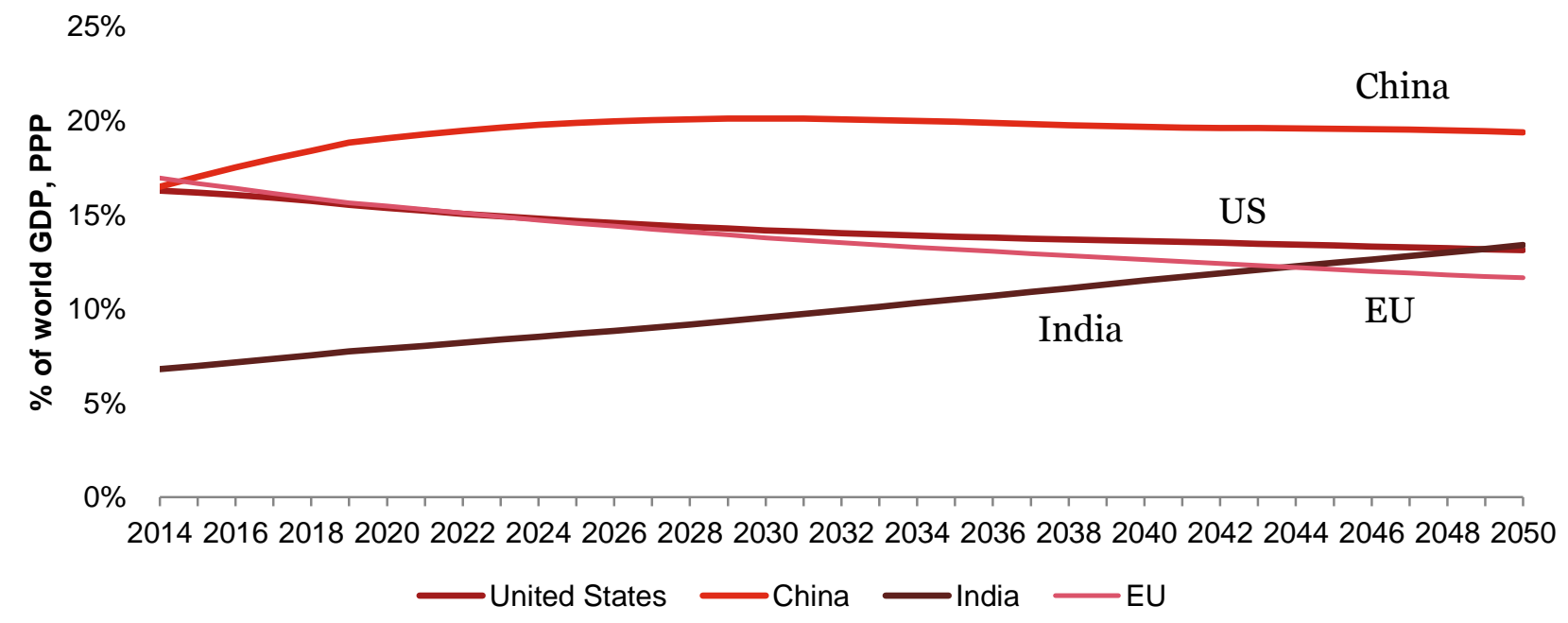

Source: PwC analysis (based on IMF estimates for 2014) 
Of course, as we discuss further in Section 3.4 below, there are many uncertainties surrounding any such projections, so it is always worth looking at alternative scenarios. Some of these uncertainties, particularly around the future growth of world trade, are discussed in our interview with Rebecca Harding, CEO of Delta Economics (see Box 1 below).

Box 1: 'World in 2050': Interview with Rebecca Harding, CEO, Delta Economics

\section{What is your view on prospects for the key regions in the world economy? Are the growth projections in the report broadly plausible?}

Broadly yes, though growth could be flatter than projected over the next few years. In particular, Chinese growth could slow somewhat more than expected as it reorients from export-led to domestic-led growth. But after around 2018, growth could get back on track both in China and in emerging Asia more generally, in part because China will be pushing its productive capacity into other lower cost places like Vietnam, Indonesia, the Philippines and maybe also Myanmar.

The US economy has decent prospects, supported by some re-shoring of manufacturing from China and elsewhere. This is also benefiting Mexico, though other Latin American economies continue to disappoint due to lack of infrastructure investment and continuing governance problems.

Eurozone growth remains fragile, though much depends here on how far Germany is prepared to play a leadership role. It has the fiscal space to increase infrastructure investment significantly, which would benefit both Germany's economy and its trading partners more generally, so I'd hope to see some positive action there soon.

The Gulf is an interesting area as economies like Saudi Arabia, Qatar and Dubai seek to reduce their dependence on oil and establish themselves as a general trading hub, having made large investment in ports and other transport infrastructure in recent years. But the wider Middle East is clearly still a source of considerable instability given the ongoing conflicts in Syria and Iraq, which also have adverse knock-on effects on Turkey.

I would agree that Africa has great growth potential, though it is a very diverse continent and recent events such as the Ebola crisis in West Africa and the threat to Nigerian growth from recent oil price falls are a reminder of the risks that exist there.

\section{What would you see as the key risks to growth in the longer term?}

At present there is a 'febrile stability' in the world economy, but there are clearly plenty of risks around from a sharper slowdown in China through to escalating conflicts in the Middle East and growing tensions between Russia and the US.

Looking beyond 2020, I think the key risks relate to the tectonic shifts that are occurring to the global balance of economic and geopolitical power. The US is no longer the single dominant superpower and needs to act more co-operatively in conjunction with China and a German-led Europe. I'm cautiously optimistic here, but there is clearly a lot of uncertainty about how these key geopolitical relationships will evolve.

\section{Would you see world trade growth broadly following GDP growth or diverging from it?}

All through the post-war era from 1945 to around 2011, we did see a broadly consistent relationship between world trade and GDP growth, but our analysis shows evidence of this diverging over the past three years. World trade growth appears to have slowed down significantly relative to GDP growth since 2011 and I think this could prove to be a longer term trend.

One key reason for this relates to how large multinational companies are responding to national policy environments. These often require international companies to establish local operations and alliances with local firms, rather than just exporting to a country. The consequence is that trade flows may be dampened, although against this foreign direct investment flows could grow more rapidly - and this is what we are seeing in the data.

\section{How should businesses in advanced economies react to these global economic trends?}

The growth of emerging and developing economies offers great opportunities but it also requires businesses to take on greater risks. Rather than just exporting to a country, you will need to set up operations there and the financing for this may not be so readily available for this from banks, particularly for small and medium-sized companies. So a greater degree of self-financing may be needed and risks will be correspondingly greater. 


\section{Beyond the top 3 countries}

Figure 9 below shows in graphical form the rankings of the 32 countries covered by this report in 2014, 2030 and 2050 in terms of GDP at PPPs (according to our model). The red lines denote countries which see an increase in their rankings in 2050 compared to 2014 according to our model 9 , and the grey lines denote countries which see a drop in their rankings.

As discussed earlier in the report, China has already overtaken the US for the number one spot, and will remain as the world's largest economy in 2050. India could narrowly overtake the US for the number two spot by 2050. However, the gap between the third largest economy and the fourth largest economy will widen considerably. In 2014, the third biggest economy (India) is around 50\% larger than the fourth biggest economy (Japan). In 2050, the third biggest economy (the US) is projected to be approximately $240 \%$ larger than the fourth biggest economy (Indonesia).

Closer inspection of Figure 9 shows that most developed countries are projected to experience a drop in rankings (i.e. grey lines), whilst most developing countries and emerging economies are projected to experience a rise in rankings (i.e. red lines). In particular:

- Our model projects that Indonesia (9th in 2014) and Brazil (7th in 2014) could rise to amongst the top 5 largest economies by 2050 in terms of GDP at PPPs;

- Other notable developments are that Mexico (11th in 2014) and Nigeria (20th in 2014) are projected to rank 6th and 9th respectively by 2050 in terms of GDP at PPPs. The UK is expected drop from 10th to 11th by 2050 given that it is a relatively mature and advanced economy, although it holds its place relatively well compared with other advanced economies;

- Colombia is another economy that performs well in terms of relative growth rates compared to other Latin American economies, though it does not rise that far up the global GDP rankings where it has to compete with even faster growing Asian economies. Nonetheless, its prospects appear relatively bright, as discussed in detail in Box 2.

- Poland also does well relative to Russia and Germany (see Box 3), though it inevitably slips down the global rankings due to its relatively small population size compared to rising Asian economies in particular.

\footnotetext{
9 For simplicity, we have also used red lines to denote countries that do not experience a change in rankings.
} 
Figure 9: GDP at PPP rankings

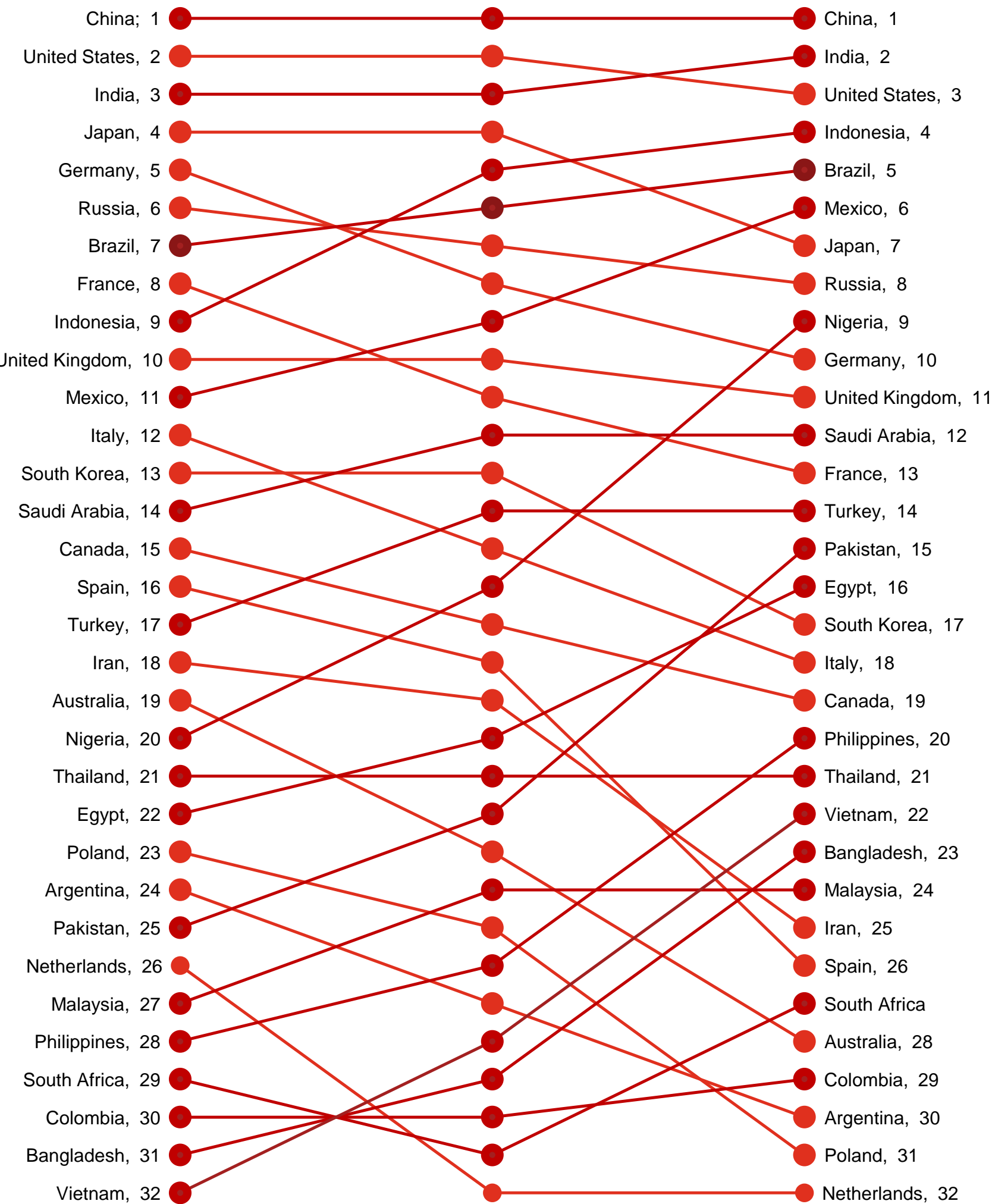

Source: IMF estimates for 2014, PwC projections for 2030 and 2050 


\section{Box 2: Commentary on long-term growth projections for Colombia}

The Colombian economy has achieved stable growth in the last few years as evidenced by GDP growth rates of $4 \%$ in 2012, $4.7 \%$ in 2013 and a target by the Colombian government of $4.7 \%$ in 2014 and $4.5 \%$ in $2015^{10}$.

This growth has been driven by the construction, financial services, mining and hydrocarbons sectors ${ }^{11}$. These last two sectors have had an important role in driving Colombian economic growth in past years, though decreasing their contribution since 2013. But commodities such as coal and crude oil, which are the two main sources of Colombia's export earnings, remain important to the economy.

Other aspects which have helped to create the environment for stable growth of the economy have been:

1. Controlled inflation of $3.2 \%$ in $2012,2 \%$ in 2013 and $3.6 \%$ in 2014;

2. A reduction of the unemployment rate to $9.6 \%$ in 2013 with a target of $8.9 \%$ for $2014^{12}$;

3. An improvement in credit rating to investment grade level (S\&P BBB, Moody's Baa2, Fitch BBB);

4. Growing inward foreign direct investment of around \$15 billion in 2012 and around \$16 billion in 2013.

Colombia has also been working to open up its economy, with 13 different free trade agreements in force as of

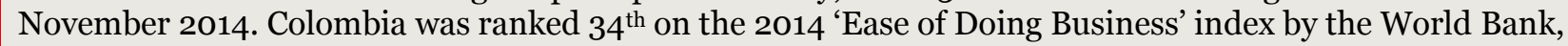
improving 13 positions from 2013 and being the leading economy in Latin America on this index.

For the coming years the Colombian government has embarked on policies aimed at consolidating peace in the country, and improving equity and the quality of education ${ }^{13}$. Another priority of the government is to join the OECD and it is therefore undertaking a series of reforms in order to meet required OECD standards.

Our projections suggest a medium-term annual growth rate of around $4.5 \%$ could be achievable over the period to 2020 for Colombia if the Government's reform plans can be delivered. This is similar to the medium term projections of the IMF (4.5\% in 2019) ${ }^{14}$.

This growth will be based not only on maintaining strong and stable performance on key macroeconomic indicators, but also through realising the productive benefits that the Fourth Generation $(4 \mathrm{G})$ telecoms infrastructure programme and peace talks could bring. Together these could produce a positive multiplier effect on sectors such as agriculture and manufacturing, giving a further boost to growth.

\section{Gustavo F. Dreispiel, Clients and Markets partner, PwC Colombia,} (gustavo.f.dreispiel@co.pwc.com)

\footnotetext{
${ }^{10}$ Colombia National Department of Planning (DNP)

${ }^{11}$ Colombia National Administrative Department of Statistics (DANE)

${ }^{12}$ Colombia National Development Plan 2014-2018

${ }_{13}$ Colombia National Development Plan 2014-2018

14 International Monetary Fund, World Economic Outlook (October 2014)
} 


\section{Box 3: Commentary on long-term growth projections for Poland}

According to our latest model projections, Polish GDP will grow at an average real rate of around $2.7 \%$ per annum over the period to 2050. This is very similar to the projected long-term growth rate in our January 2013 report (2.5\%), reflecting that the long term economic fundamentals on which our model is based are not subject to short-term fluctuations that could seriously alter the results obtained within a two-year period.

As before, Polish growth is projected to slow over time from $3.4 \%$ per annum on average in 2014-20 to $2.8 \%$ per annum in 2021-40 and around $2 \%$ per annum in 2041-50. This reflects Poland's ageing population and the fact that, once catch up is achieved with the advanced economies, further rapid growth will become more challenging.

Poland's projected long term annual growth rate of 2.7\% in 2014-50 continues to compare favourably with those of Germany (1.6\%) and Russia (2.1\%). This reflects positive Polish economic characteristics such as: relatively attractive labour costs accompanied by an increasing quality of human capital, and relative political and economic stability. Continued restructuring of the economy from labour intensive low-tech production to mid-tech production and assembly of high-tech products should suffice to ensure a relatively dynamic pace of growth in the medium term.

Additional efforts are necessary to continue reasonably high growth rates in the longer run. Polish enterprises have to be able to move to higher value-added ends of production chains in technology-intensive sectors. This can only be achieved through high levels of investment in R\&D activities and other forms of innovation. These efforts can be effectively financed only by local savings. From a macroeconomic point of view, the high current account deficits recorded recently by Poland are not sustainable in the long run. At the microeconomic level, globalising Polish companies have to be actively encouraged by public policy to run their R\&D and innovation activities in co-operation with local small and medium-sized companies and academic institutions.

If the Polish economy is not to slow down in the longer term it has to be able to 'breed' its own global players, with their R\&D, innovation, investment decision-making and financial centres located in the country. High risk investments needed to develop innovative industries require a strong innovation network, supported by an appropriate public policy regime. These long run challenges would be at the top of the policy agenda if we continued to live in the politically stable environment seen two or three years ago. However, the political turmoil in Ukraine, accompanied by the ongoing problems in the Eurozone economy, potentially have both negative and positive consequences that need to be managed by economic decision makers.

The negatives seem to be obvious. Polish companies have had to face direct and immediate effects such as Russian import bans and a serious drop in the size of the Ukrainian market. General economic instability in the region has also had a negative influence on the Polish exchange rate and could also have some adverse impact on the propensity of global companies and funds to invest in Central and Eastern Europe. In general, however, these negative consequences are mainly short and medium term and, even if they materialised, they should not have serious consequences for the long-term growth potential of the Polish economy.

The positive consequences, by contrast, could have a long term impact. Just as the 1998 Russian crisis resulted in a major switch in the direction of Polish exports from east to the west, so this new crisis could result in an accelerated process of diversification of energy resources with a potentially significant positive impact on the long term competitiveness of the largest Polish enterprises.

Political instability accompanied by the Eurozone economic crisis can also help to explain the growing tendency to replace 'offshoring' by 'nearshoring'. Poland is an attractive destination for such operations. However, bearing in mind the long-term challenges described above, the Polish government should aim to attract investments that have positive technological spillovers in the long term as well as creating jobs in the short term.

Mateusz Walewski, Senior Economist, PwC Poland (mateusz.walewski@pl.pwc.com) 


\subsection{Projected real GDP growth}

Figure 10 below shows the average real GDP growth p.a. for each of the 32 countries covered in the 'World in 2050' for the period from 2014 - 2050. We have broken down each country's growth into two components:

1. Average population growth; and

2. Average growth in GDP per capita, which is closely related to labour productivity growth.

Figure 10: Breakdown of components of average real growth in GDP at PPPs (2014 - 2050)

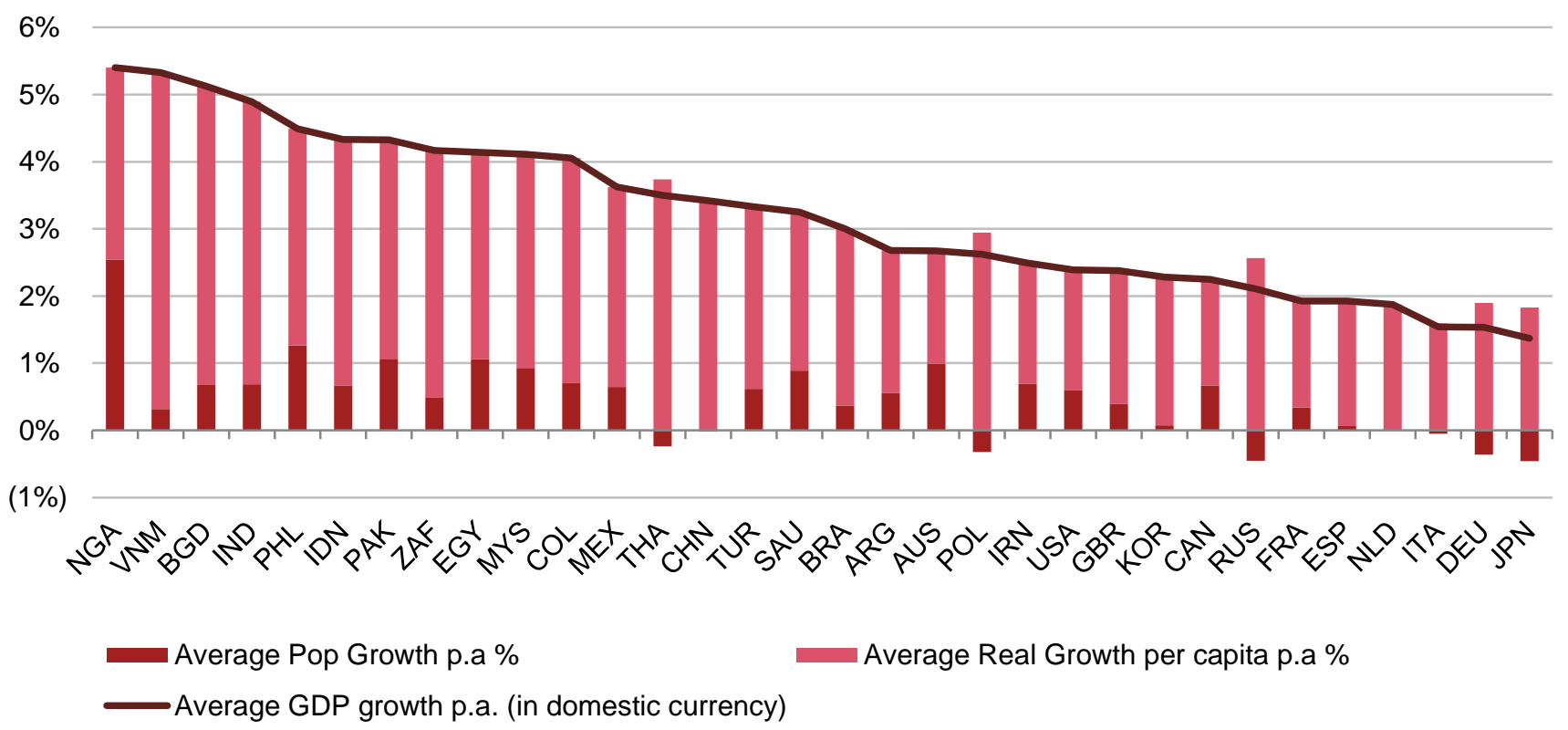

Source: PwC analysis

Figure 10 above and Table 2 below show that:

- The top ten fastest growing economies are all developing countries: seven are from South and Southeast Asia and three are from Africa;

- Our model projects that Nigeria and Vietnam could have the highest average real GDP growth per annum during the whole period to 2050:

- $\quad$ Nigeria has the potential to be a fast growing country due to its youthful and growing working population (see Box 6 in Section 4 below for more details on its outlook). However, this does rely on using Nigeria's oil wealth to develop a broader based economy with better infrastructure and institutions (e.g. rule of law and political governance) to support long term productivity growth - the potential is there, but it remains to be realised in practice ${ }^{15}$.

- Our model projects that Vietnam could grow at an average annual rate of 5.3\%. However, in order to realize this, Vietnam needs stronger macroeconomic policy frameworks to realize this potential.

${ }_{15}$ This point could also be applied to Africa generally, as our chief economist John Hawksworth argued in this blog post: http://pwc.blogs.com/ceoinsights/2014/12/can-africa-fulfil-its-growth-potential.html 
- Most of the developed economies are expected to experience low levels of population growth. Japan and Germany will experience negative population growth on average during the period $2014-2050^{16}$.

Demographics are now actually a drag on growth in the long term for these developed economies. This can also be seen in nations such as Poland and Thailand. This brings into sharp perspective the importance of structural reforms and institution building aimed at boosting the productivity element of growth in the absence of high population growth.

- China's growth is expected to moderate sharply in the medium term - our model projects that China will grow at an average annual rate of 3.4\% during the period $2014-2050$. Given China's low population growth and aging population (accentuated by its one-child policy for the past three decades), increases in labour productivity will account for all of its economic growth (in fact, China is expected to experience a very minor decline in its population during the period $2014-2050$ ).

Table 2: Breakdown of components of average real growth in GDP (2014 - 2050)

\begin{tabular}{|c|c|c|c|}
\hline Country & $\begin{array}{l}\text { Average Population } \\
\text { growth p.a \% }\end{array}$ & $\begin{array}{l}\text { Average Real Growth } \\
\text { per capita p.a \% }\end{array}$ & $\begin{array}{l}\text { Average GDP growth p.a. (in } \\
\text { domestic currency) }\end{array}$ \\
\hline Nigeria & $2.5 \%$ & $2.9 \%$ & $5.4 \%$ \\
\hline Vietnam & $0.3 \%$ & $5.0 \%$ & $5.3 \%$ \\
\hline Bangladesh & $0.7 \%$ & $4.4 \%$ & $5.1 \%$ \\
\hline India & $0.7 \%$ & $4.2 \%$ & $4.9 \%$ \\
\hline Philippines & $1.3 \%$ & $3.2 \%$ & $4.5 \%$ \\
\hline Indonesia & $0.7 \%$ & $3.7 \%$ & $4.3 \%$ \\
\hline Pakistan & $1.1 \%$ & $3.3 \%$ & $4.3 \%$ \\
\hline South Africa & $0.5 \%$ & $3.7 \%$ & $4.2 \%$ \\
\hline Egypt & $1.1 \%$ & $3.1 \%$ & $4.1 \%$ \\
\hline Malaysia & $0.9 \%$ & $3.2 \%$ & $4.1 \%$ \\
\hline Colombia & $0.7 \%$ & $3.4 \%$ & $4.1 \%$ \\
\hline Mexico & $0.6 \%$ & $3.0 \%$ & $3.6 \%$ \\
\hline Thailand & $-0.2 \%$ & $3.7 \%$ & $3.5 \%$ \\
\hline China & $0.0 \%$ & $3.4 \%$ & $3.4 \%$ \\
\hline Turkey & $0.6 \%$ & $2.7 \%$ & $3.3 \%$ \\
\hline Saudi Arabia & $0.9 \%$ & $2.4 \%$ & $3.2 \%$ \\
\hline Brazil & $0.4 \%$ & $2.6 \%$ & $3.0 \%$ \\
\hline Argentina & $0.6 \%$ & $2.1 \%$ & $2.7 \%$ \\
\hline Australia & $1.0 \%$ & $1.7 \%$ & $2.7 \%$ \\
\hline Poland & $-0.3 \%$ & $2.9 \%$ & $2.6 \%$ \\
\hline Iran & $0.7 \%$ & $1.8 \%$ & $2.5 \%$ \\
\hline United States & $0.6 \%$ & $1.8 \%$ & $2.4 \%$ \\
\hline United Kingdom & $0.4 \%$ & $2.0 \%$ & $2.4 \%$ \\
\hline South Korea & $0.1 \%$ & $2.2 \%$ & $2.3 \%$ \\
\hline Canada & $0.7 \%$ & $1.6 \%$ & $2.2 \%$ \\
\hline Russia & $-0.5 \%$ & $2.6 \%$ & $2.1 \%$ \\
\hline France & $0.3 \%$ & $1.6 \%$ & $1.9 \%$ \\
\hline Spain & $0.1 \%$ & $1.9 \%$ & $1.9 \%$ \\
\hline
\end{tabular}

\footnotetext{
${ }^{16}$ This is despite the UN population projections that we use assuming continued net migration to these countries.
} 


\begin{tabular}{lccc} 
Country & $\begin{array}{c}\text { Average Population } \\
\text { growth p.a \% }\end{array}$ & $\begin{array}{c}\text { Average Real Growth } \\
\text { per capita p.a \% }\end{array}$ & $\begin{array}{c}\text { Average GDP growth p.a. (in } \\
\text { domestic currency) }\end{array}$ \\
Netherlands & $0.0 \%$ & $1.9 \%$ & $1.9 \%$ \\
\hline Italy & $-0.1 \%$ & $1.6 \%$ & $1.5 \%$ \\
\hline Germany & $-0.4 \%$ & $1.9 \%$ & $1.5 \%$ \\
\hline Japan & $-0.5 \%$ & $1.8 \%$ & $1.4 \%$ \\
\hline
\end{tabular}

Source: PwC analysis

China's economy is expected grow at an average annual rate of $6.3 \%$ for the remainder of this decade, but with a marked deceleration in the longer term beyond 2020. This is because, as China's economy continues to mature, it is expected to transition from being an export-led to a consumption-driven economy. This process will be sped up by a rapidly aging population and increasing real labour costs. Western companies will also likely see a change in the way they do business in the Asian region. Rising costs will mean that many off-shored jobs are likely to exit China over time and move to other cheaper economies such as Vietnam, Bangladesh, Philippines and Indonesia, whilst Chinese exporters will find themselves competing more on the basis of quality rather than price in their key US and EU export markets.

Similarly, the Indian economy is projected to grow at an average annual rate of $6.4 \%$ in $2014-2020$, but is likely to see some moderation in the longer term. However, its average growth rate should remain stronger than China after 2020 due to its younger population and greater scope for catch-up growth. This great potential was discussed in more detail in a recent PwC report on India's future ${ }^{17}$, but does require sustained economic reforms and increased investment in infrastructure, institutions and mass education (notably for women in rural areas).

Figure 11: Growth projections for the BRICs, US, UK, EU and the World

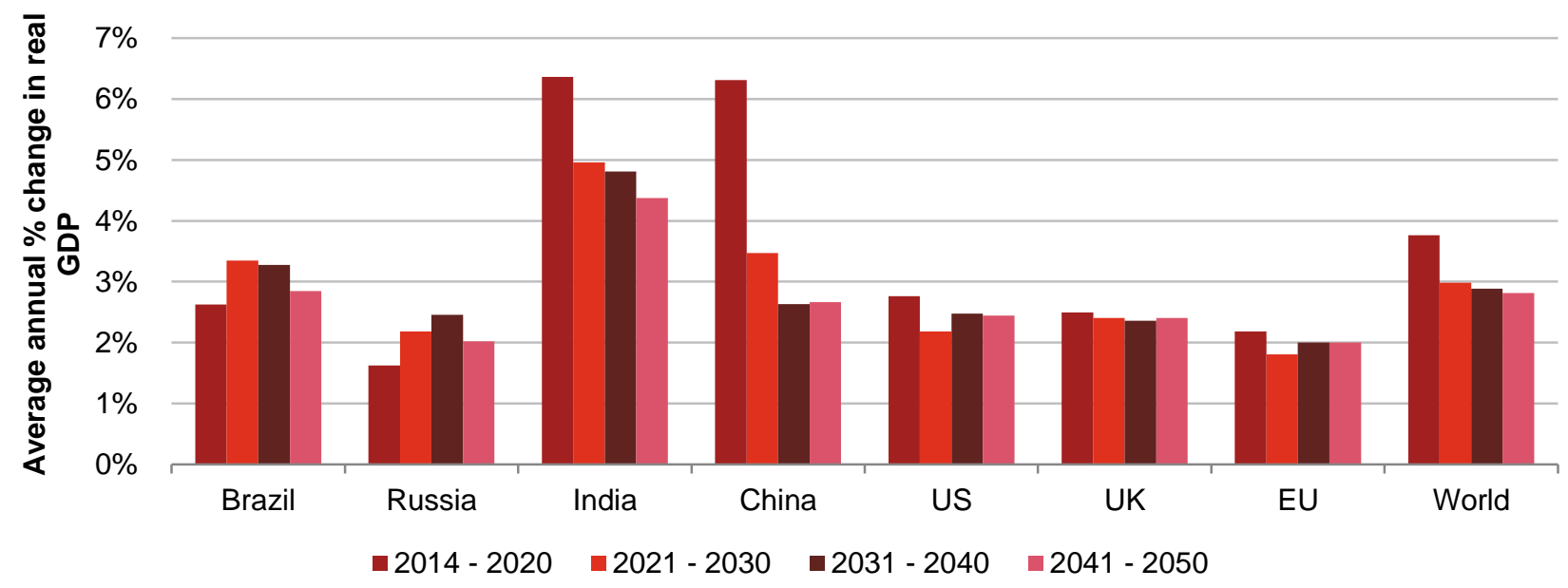

Source: PwC analysis

It is worth emphasising here that the Asian century will not just be built by China and India. There are many other vibrant economies in the region, including Malaysia as discussed in detail in Box 4 below.

${ }^{17}$ Future of India: the Winning Leap, PwC, November 2014: http://www.pwc.in/thewinningleap 


\section{Box 4: Commentary on long-term growth projections for Malaysia}

We retain our view from the January 2013 edition of this report that Malaysia's growth rate has the potential to perform even better than the model results, which already show relatively healthy average real GDP growth of around 5\% per annum up to 2020 and around $4.2 \%$ average annual real growth over the whole period to 2050 .

Our view has been strengthened by a few key developments since the January 2013 edition.

First, the Malaysian government has taken concrete steps to strengthen the public finances, which is important for long-term sustainable growth.

Specifically, in the most recent Budget 2015, the government reaffirmed its commitment to fiscal consolidation and reform. The Budget confirms the introduction of GST which, combined with subsidy rationalisation, is expected to raise the government's operating budget surplus. This creates a broader tax base to support the government's growth agenda.

Second, the implementation of initiatives to overcome key growth constraints is progressing successfully. These initiatives range from infrastructure investment to human capital development.

The Klang Valley MRT project is progressing well and, when operational, should deliver significant economic benefits through traffic congestion alleviation. Increasing the ability of workers and residents to move around the capital city more efficiently results in greater connectivity, creating deeper markets for people and ideas and thereby enhancing productivity.

Budget 2015 also signalled a strong commitment to developing human capital and entrepreneurship. Malaysia has great potential to benefit from the demographic dividend and recent measures demonstrate that it is on the right track to realise this potential through investment in job creation, improving education, enhancing the quality of labour, encouraging savings and developing a more inclusive economy. Our initial analysis suggests that this demographic dividend can last up to two decades.

Third, the reform agenda to create a better business environment continues apace.

The World Bank in its latest report confirmed that the government's efforts and commitment to enhancing Malaysia's business environment is on the right track. Malaysia has improved its ranking from 20th in 2013 to 18th in 2014. The latest study finds Malaysia as the second highest ranked ASEAN country in the index. Our own 2014 Escape Index also shows Malaysia as one of the best performing emerging economies on a range of economic, social, political, technological and environmental indicators ${ }^{18}$.

Last but not least, greater ASEAN integration and proposed trade deals with China and other Asia-Pacific trade partners will enhance Malaysia's ability to benefit from these global growth engines.

Malaysia is favourably located in the middle of a $\$ 2$ trillion+, 600 million+ person ASEAN market and in between China and India, the two most significant drivers of future global economic growth. Malaysia's goods exports to BRIC countries have increased at an average rate of around $15 \%$ per annum over the $2000-13$ period, much faster than the average for exporters to these countries. Following the greater ASEAN economic integration that is expected by 2016, Malaysia is poised to benefit further from its geographical position as well as its highly developed logistics and trade infrastructure.

This is recognised by global investors, who (aside from a sharp dip in 2009 due to the global financial crisis) have steadily increased their capital inflows to Malaysia over time as the chart below shows.

\footnotetext{
${ }^{18} \mathrm{http}$ ///www.pwc.co.uk/economic-services/issues/escape-index-mapping-how-markets-emerge.jhtml
} 
Figure 12: Global FDI inflows into Malaysia

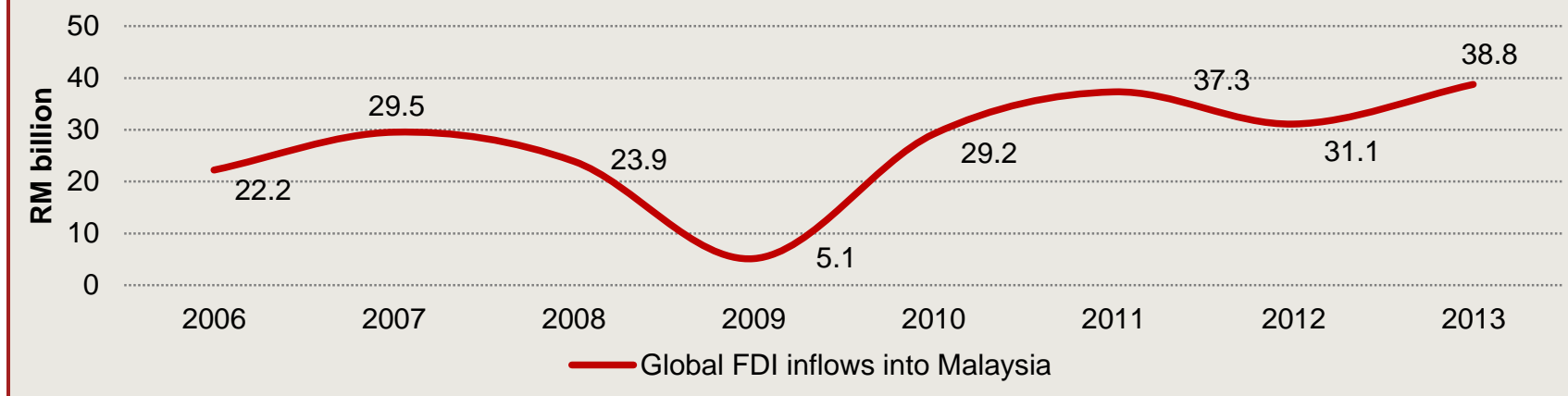

Source: MITI, Department of Statistics Malaysia

Patrick Tay, Executive Director, Economics Advisory, PwC Malaysia

(Patrick.se.tay@my.pwc.com )

\subsection{Relative income levels}

Figure 13 below shows the GDP per capita in PPP terms for the G7 economies plus Australia, Spain and South Korea, and the E7 economies. Although many of the emerging economies are projected to overtake the developed countries in terms of overall size and rate of growth, Figure 13 below shows that the E7 countries still lag well behind the G7 countries in terms of GDP per capita even in 2050.

Figure 13: GDP per capita in PPP terms for the G7 and E7 economies

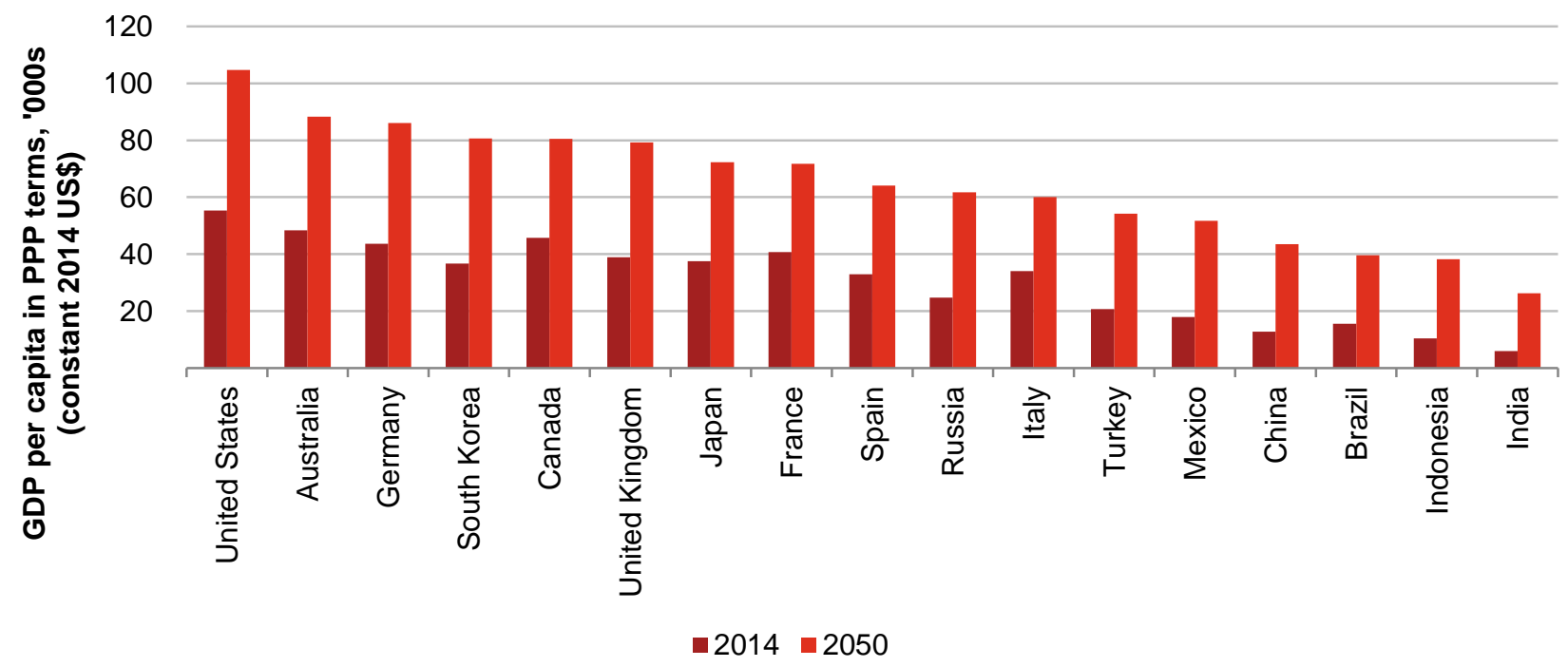

Source: PwC analysis 
The US sits at the top in 2050, whilst large emerging economies such as China, India, Brazil and Indonesia still sit at the bottom of the rankings in terms of GDP per capita in PPP terms. However, the gap between the top and bottom is expected to narrow significantly. For example, in 2014, China's GDP per capita in PPP terms is $23 \%$ of the US level - by 2050, China's GDP per capita is projected to be $42 \%$ of the US level. The reason that a gap remains is that these average income divergences have built up over the past 250 years, so they will take much more than 35 years to completely close again. Therefore, despite the rising middle class of emerging economies such as China and India, the consumption powers of an emerging economy will still be considerably smaller relative to a developed economy with around the same population. Companies will need to take this into consideration when developing their growth strategies (as discussed further in Section 4.2 below).

\subsection{Scenario analysis}

As noted above, any such long term projections are subject to many uncertainties, so it is important to consider some alternative scenarios, focused in particular here on downside risks (although there also could be some upside risks to our projections). Figure 14 below shows our model projections for the G7, E7 and the world's average annual growth rate in our downside scenarios. We have devised three such scenarios, each one building on the assumptions made in the previous one:

1. Scenario 1: trend annual US labour productivity growth decreases by 0.5 percentage points (representing a deceleration in global technological progress within the structure of our model);

2. Scenario 2: Convergence rates reduced by half, and trend annual US labour productivity growth decreased by 0.5 percentage points; and

3. Scenario 3: Investment to GDP ratios decrease by a quarter, convergence rates decrease by half and annual trend US labour productivity growth decreases by 0.5 percentage points.

It should be noted that, although these scenarios reflect the model structure (i.e. US labour productivity, convergence rates and investment to GDP ratios are key inputs into our model that we can adjust to conduct sensitivity and scenario analysis), they also indirectly reflect the impact of a broader range of risks.

For example:

- Political instability could dampen investment catch-up rates for the emerging markets. We provide a more in depth discussion on the impact of institutions on economic growth and its implications in Section $\mathbf{0}$;

- Possible future rises in energy and raw materials could be reflected in reduced investment rates in energyintensive sectors, and is therefore indirectly reflected in Scenario 3.

Figure 14: Average annual growth rates of the G7, E7 and the world for downside scenarios

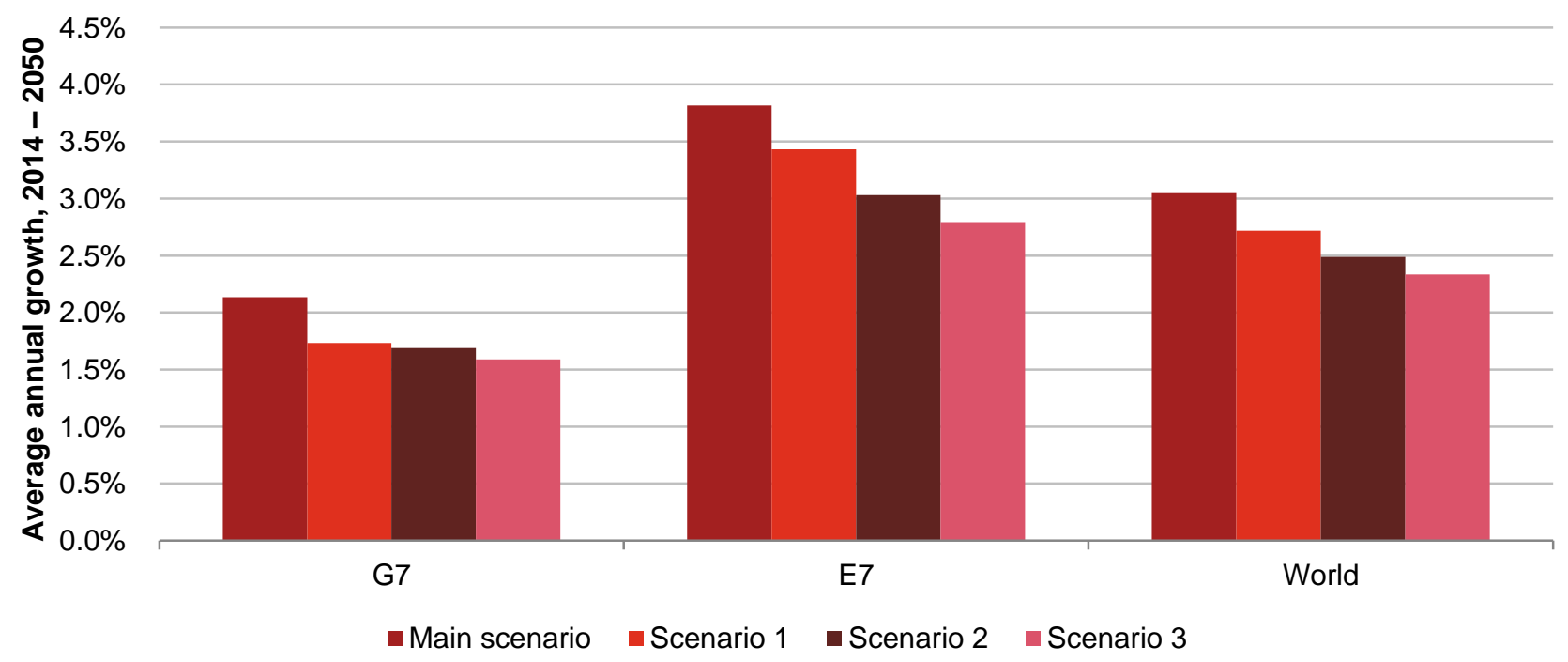

Source: PwC analysis 
This analysis shows that:

- In Scenario 3, which can be considered a severe downside scenario where US labour productivity, convergence rates and investment all decrease, average annual growth rates for the G7, E7 and the world would fall by $0.5,1.0$ and 0.7 percentage points respectively. In terms of the size of economy (i.e. level of GDP in PPP), the G7, E7 and the World's GDP in 2050 in scenario 3 would be around $18 \%, 30 \%$ and $22 \%$ smaller when compared with their GDP levels in 2050 in the main scenario;

- A scenario where US labour productivity decreases by 0.5 percentage points hits the G7 economies relatively more than the combined impact of a scenario where investment to GDP ratios decrease by $25 \%$ and convergence rates decrease by 50\% (-0.4 percentage points compared with - 0.1 percentage points respectively). The E7 economies, by contrast, are more sensitive to reduced convergence rates.

Some further insights on the risks facing the global economy, with particular reference to the banking and financial sectors, are provided in the interview with Richard Woolhouse in Box 5 below.

Box 5: 'World in 2050': Interview with Richard Woolhouse, Chief Economist, British Bankers' Association

\section{Are the growth projections in the report broadly plausible? Any major surprises?}

The growth projections in the report look broadly sensible. I am slightly surprised to see that Saudi Arabia, Russia and Nigeria are doing so well in the rankings in the year 2050, given that these countries are very reliant on oil and gas revenues, which could be a limiting factor unless they can successfully diversify their economies in the longer term. Other than that, I do not find any major surprises with the growth projections.

\section{What would you see as the key risks to achieving these projected growth rates?}

One risk relates to the 'de-globalisation' in the global banking and financial system after the 2007-8 crisis, in part a response to regulatory changes. Cross-border capital flows have decreased significantly, and the EU accounts for much of this drop as financial integration in the region has gone into reverse. The regulatory changes raise challenges for the global universal banking model, and more focused banks are currently more profitable post-crisis.

The risk of a reversal in financial globalisation is being exacerbated by the lack of global governance in key areas. International bodies such as the FSB (Financial Stability Board), BCBS (Basel) and IOSCO lack the legal powers to regulate the global financial system in the same way as, say, the WTO can do for global trade.

If the world economy does evolve broadly as envisaged here, will there be a corresponding shift in banking power to China, India and other emerging economies?

If we look at data on the size of banks in terms of assets around the world, I believe that this shift is already happening. Although this trend is somewhat similar to what we saw in Japan in the 1980 and early 1990 , where it had the biggest banks in the world before its land price bubble burst, it is less likely that there will be a repeat of this in China for two main reasons. First, the Chinese government still has a lot of fiscal space, and so it could still maintain a sustainable public debt-to-GDP ratio even if it had to take on bad debts from failing banks. Second, the Chinese government has greater control over the process of debt creation within the Chinese banking system. There is also the potential for reforming state enterprises in a way that could boost performance of the Chinese economy in the long run and allow the major banks to switch their lending activity to private companies and households. 


\section{Are there any risks and challenges for the global banking system in the future? What about regulators?}

As mentioned before, the current global institutional structure which governs and monitors the global banking system still needs further development in order to promote the international cooperation required to foster a healthy global banking system. There is also some trend towards the 'nationalisation' of the regulatory framework, as banking regulators focus increasingly more on domestic problems.

The shift in global banking power towards emerging economies also has implications on who holds regulatory power - the current FSB agenda and new rules for the financial system are currently being written mostly by the West, but this may well be the last time this occurs.

\section{What could be the longer term impact of technological change on banking and finance?}

Technology will play a big role and could fundamentally change the way that the financial system works. Although it is very difficult to predict exactly how this will play out, both banking and particularly the asset management industry could be particularly ripe for disruption. Advances in digital technology could enable more and more people to move towards self-directed investment using online platforms, fundamentally changing how the current industry works. I see this as a huge growth area going forwards for new entrants. There is also an interesting question as to where technological innovation will come from in future.

Traditionally, it has mostly come from areas like Silicon Valley, but with success stories such as Alibaba in China, it may be the case that we will start to see more innovation coming from the East. This will reinforce other factors shifting global economic power in that direction. 


\section{Institutional challenges and business implications}

\subsection{Escaping the middle income trap - the critical role of institutions}

We have argued in this report that the E7 economies still have great long term potential, but the last couple of years have seen some of them falter. Chinese growth has slowed, Russia's has stalled and previously high performing economies like India, Indonesia, Brazil and Turkey have encountered considerable market turbulence since mid-2013.

As a result, both companies and investors have woken up to the fact that emerging markets remain relatively risky places to do business. In fact, PwC's Country Risk Premium (CRP) Model ${ }^{19}$ shows that the E7 countries have exhibited significantly higher risks than the G7 economies as Table 3 below illustrates for the latest available data. Persistent weaknesses in the E7's political, economic and social institutions underlie the most serious of these risks.

Table 3: PwC Country Risk Premia (CRP) for the G7 and E7

\section{Average CRP}

G7
$0.3 \%$

$2.0 \%$
GDP-Weighted Average CRP

$0.2 \%$

$1.6 \%$

Source: PwC analysis for Q3 2014 (risk premia are measured relative to a US benchmark of zero)

We have also sought to address this issue through the PwC ESCAPE Index ${ }^{20}$, which was first launched in February 2014 and has since been updated for this report. This aims to provide a holistic view of the performance of 42 of the largest advanced and emerging economies since 2000. The index combines 20 key indicators across five dimensions:

1. Economic growth and stability;

2. Social progress and cohesion;

3. Communications technology;

4. Political, legal and regulatory institutions; and

5. Environmental sustainability.

\footnotetext{
19 PwC's Country Risk Premium (CRP) analysis covers 187 sovereign nations using an economic model that PwC have developed since 1998. PwC's model uses a range of inputs in generating CRPs, including reliable sources of credit and risk ratings and sovereign bond information. The CRPs are updated on a quarterly basis. For more information, please visit http://www.pwc.co.uk/theeconomy/issues/country-risk-premia-quarterly-update.jhtml for our latest CRP update.

${ }^{20}$ For more details of our ESCAPE index see: http://www.pwc.co.uk/economic-services/issues/escape-index-mapping-how-marketsemerge.jhtml
} 
The quality of institutions enters most directly into the fourth of these categories, but also has important indirect influences on the other four dimensions. For example:

- An independent and credible central bank can help to keep inflation under control and reduce the risk of overheating that leads to balance of payments and currency crises;

- A fair and efficient tax regime can provide the funds necessary to support key social developments such as schools and hospitals, as well as providing a clear, stable regime within which to do business;

- An appropriate degree of intellectual property rights protection can stimulate technological progress and other forms of innovation;

- Effective environmental regulation can promote sustainable long-term growth; and

- High levels of trust (as measured by results from the World Values Survey that are included in our index) can boost social cohesion and have more general benefits in facilitating economic transactions of all kinds.

A particular objective of the index is to give an indication of how well different emerging markets are placed to escape the so-called 'middle income trap'. Figure 14 shows the latest index results for selected large emerging economies, as well as Sweden (the country that ranks highest on the 2013 index) and Singapore and South Korea (two countries that have graduated to advanced economy status over the past couple of decades). Saudi Arabia, Malaysia and Chile seem to be the front-runners to join them at present. China also does pretty well, but the other E7 economies (the yellow bars in the chart) are all lagging some way behind. Turkey, Brazil and India in particular are towards the bottom of the heap ${ }^{21}$.

Figure 15: PwC ESCAPE Index for 2013 - Selected countries

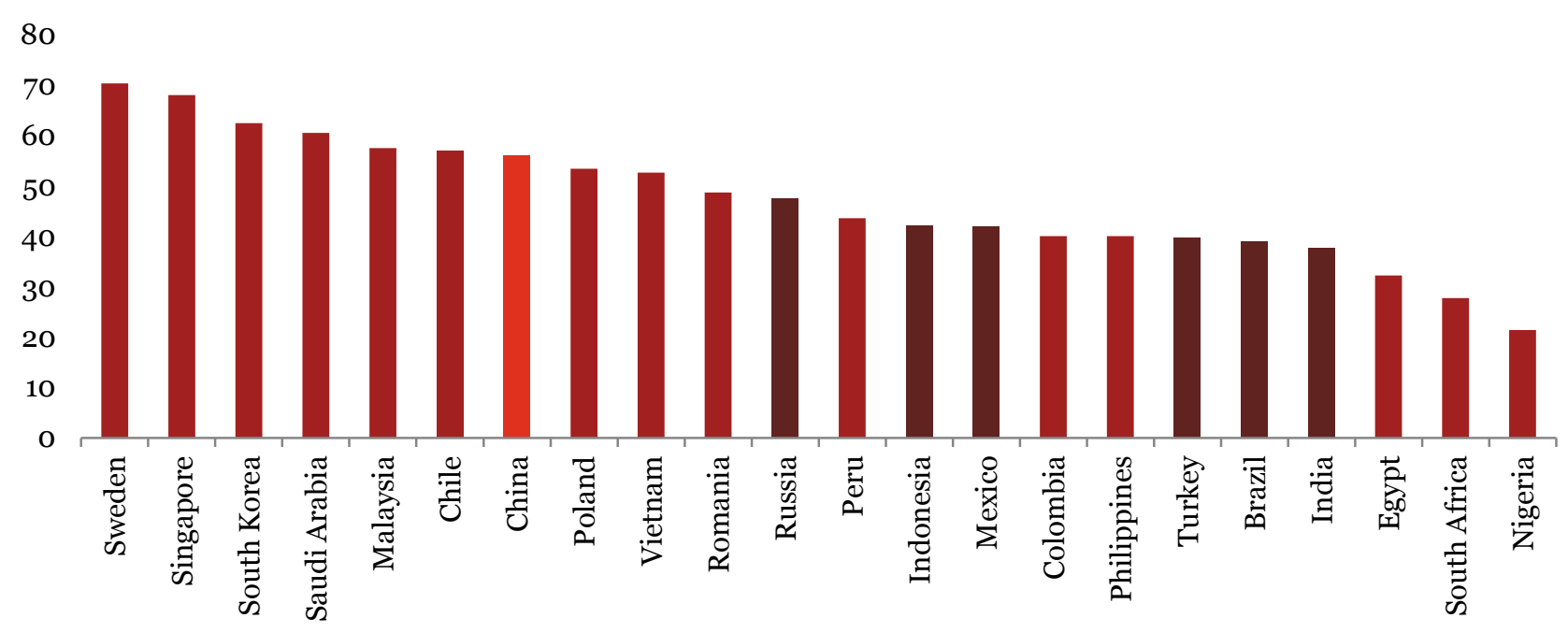

Source: PwC analysis based on data from World Bank, IMF, World Values Survey, Barro and Lee

\subsubsection{A closer look at the $E_{7}$}

What is holding the E7 back? To answer this, we need to delve further into the details of the index, looking at results for each of the 20 component indicators.

The first conclusion from this analysis is that technology is not the problem. All of the E7 have, for example, made great progress since 2000 in adopting new digital methods of communication like smart phones and broadband internet.

\footnotetext{
${ }^{21}$ South Africa and Nigeria rank lowest of the 42 large economies in our index, which primarily reflects their institutional weaknesses, despite recent strong growth performance in Nigeria in particular.
} 
Environmental sustainability is a long term concern ${ }^{22}$ in many cases, ranging from the need to protect Amazonian rainforests in Brazil to worries about rising carbon intensity in India and high levels of air and water pollution in China. But in terms of derailing economic development, the bigger concerns at present relate first to economic stability and second to political and social institutions.

We can make this more specific by identifying for each of the $\mathrm{E}_{7}$ those indicators that are either below average ${ }^{23}$ and not improving between 2007 and 2013, or about average but declining since 2007, or both. Table 3 sums up the major weaknesses of each country on this basis.

Table 4: Relative weaknesses of the E7 countries based on PwC ESCAPE Index components

Country Economic growth and stability $\quad$ Political and social institutions

\begin{tabular}{|c|c|c|}
\hline China & None & $\begin{array}{l}\text { Ease of doing business }{ }^{1} \text {, political stability }{ }^{1} \text {, rule of } \\
\text { law, income inequality }\end{array}$ \\
\hline India & Inflation ${ }^{1}$, current account deficit & $\begin{array}{l}\text { Political stability }{ }^{1} \text {, corruption }{ }^{1} \text {, rule of law }{ }^{1} \text {, income } \\
\text { inequality, ease of doing business }\end{array}$ \\
\hline Brazil & $\begin{array}{l}\text { Inflation }{ }^{1} \text {, investment to GDP ratio }{ }^{1} \text {, current account } \\
\text { deficit }^{1} \text {, government debt }{ }^{1}\end{array}$ & Low trust levels \\
\hline Russia & Investment to GDP ratio & Corruption ${ }^{1}$, income inequality \\
\hline Indonesia & Inflation $^{1}$, current account deficit ${ }^{1}$ & Corruption ${ }^{1}$, income inequality \\
\hline Mexico & GDP per capita growth ${ }^{1}$, investment to GDP ratio & Corruption $^{1}$, rule of law ${ }^{1}$, trust, ease of doing business \\
\hline Turkey & Current account deficit ${ }^{1}$ & Political stability ${ }^{1}$, income inequality, low trust levels \\
\hline
\end{tabular}

1 Both below the average for all 42 countries in 2013 and getting worse in absolute terms between 2007 and 2013 (components without a superscript qualify on only one of these two criteria).

Source: PwC analysis of ESCAPE index components for 2007 and 2013

On the economic side of the equation, all of these economies except for Mexico have delivered relatively strong growth performances over the decade to 2013 based on the conventional 'bottom line' macroeconomic indicator of GDP per capita (in PPP terms). But this growth has pumped up inflation and trade deficits in some of these economies (notably India, Brazil, Indonesia and Turkey) to levels that started to be of concern to financial market investors in 2013 and early 2014. Although these market concerns have eased somewhat at the time of writing, they could always flare up again to the extent that they indicate fundamental speed limits to economic growth without overheating.

For Brazil, low investment to GDP ratios are also of concern, and its government debt to GDP ratio is also relatively high and rising. Low investment also stands out as a relative weakness for Russia and Mexico. By contrast, China looks relatively strong on almost all economic performance measures, which is why it is the best performing E7 country on our ESCAPE index.

Although this variable is not part of the ESCAPE index, it should also be noted that Russia's high dependence on resource exports is a potentially serious structural weakness, as illustrated by the recent ruble crisis. Similar risks also apply to resource-rich economies such as Nigeria and Saudi Arabia (as noted by Richard Woolhouse in Box 5 above). Successful diversification of these economies away from natural resources will be important for their long-term success (see also Box 6 below for Nigeria).

\footnotetext{
${ }^{22}$ Of course, global warming is a major long-term global concern as discussed, for example, in our latest Low Carbon Economy Index report: http://www.pwc.co.uk/sustainability-climate-change/publications/low-carbon-economy-index.jhtml

${ }^{23}$ Relative to all 42 countries in our ESCAPE index.
} 


\subsubsection{The role of institutions}

The deeper problems, however, become apparent when we turn to political and social institutions. Research by academics such as Daron Acemoglu and James Robinson ${ }^{24}$ shows that these institutional factors can be critical to sustainable long-term growth. Where these institutions are 'extractive', a small elite may get rich, and there may be some temporary boosts to growth by reallocating resources from low to higher productivity areas (e.g. from agriculture to heavy industry in the former Soviet Union). But such countries are unlikely to graduate fully to the advanced economy club unless they reform their political, social and economic institutions to make them more inclusive and thereby provide the right incentives for innovation and entrepreneurship.

The UK moved in this direction after the Glorious Revolution of 1688 and led the way in the Industrial Revolution of the late 18th and 19th centuries. North America and Western Europe followed, as did Japan after the Meiji Restoration of 1868. Singapore and South Korea have been more recent graduates from this club, though each has followed its own particular path of economic and political development.

As Table 3 shows, the E7 have a long way to go on many key institutional measures, particularly in relation to corruption, political stability, income inequality and trust. Ease of doing business is also a major hurdle in China, India and Mexico in particular based on World Bank analysis that we have incorporated into our index.

Interestingly, very little progress has been made by the $\mathrm{E} 7$ and other emerging markets on key institutional measures 25 , even if we take the analysis back to 2000 (see Figure 15). While advanced economies, on average, lost a little ground between 2000 and 2013 on the political, legal and regulatory measures we include in our ESCAPE index, emerging markets on average have made no progress in reducing their negative score on this sub-index.

Figure 16: Political, legal and regulatory sub-index of PwC ESCAPE index for advanced and emerging economies

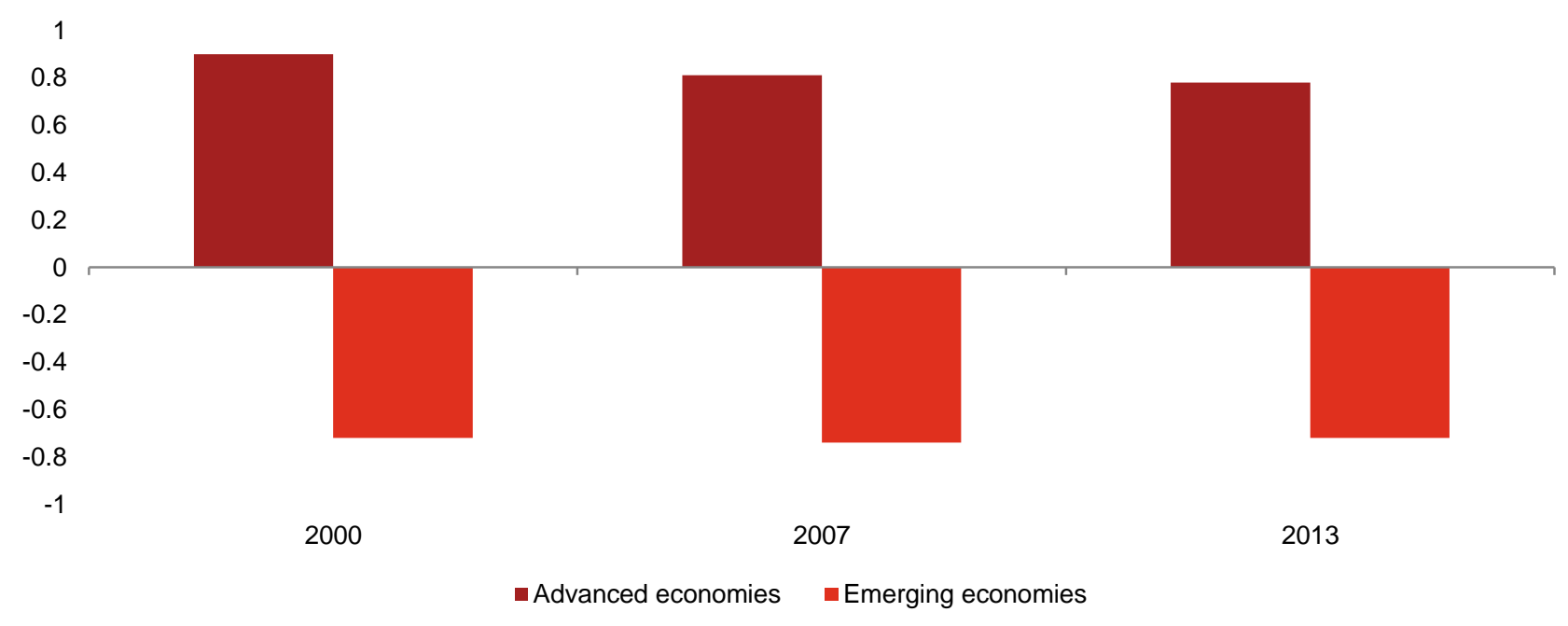

Source: Political, legal and regulatory sub-index within PwC ESCAPE index, based on data from World Bank

\footnotetext{
24 D. Acemoglu and J. Robinson,'Why Nations Fail' (2013): http://whynationsfail.com/

25 The chart shows the political, legal and regulatory sub-index within the PwC ESCAPE index, which is built up from an average of World Bank estimates relating to four factors: political stability, control of corruption, rule of law, and ease of doing business.
} 
This is in contrast to the generally strong performance of leading emerging markets on GDP growth, communications technology, rising education levels and increased average life expectancy. This suggests that making these deeper institutional advances will take a long time, even if short term macroeconomic imbalances can be addressed.

Of course, these issues do not just apply to the $\mathrm{E} 7$, but also to emerging economies more generally, not least in Africa, which has huge potential but also faces significant challenges to realise them. For example, in the case of South Africa, it has great opportunities such as a growing middle class population, an increasingly educated population (which could lead to a more productive workforce), a growing tourism industry and a relatively strong finance sector. However, it also faces major challenges, such as increasing labour market restrictions, rising income inequality, and power shortages due to a slow build-up of new capacity to meet increased energy demand.

Other African countries face similar kinds of opportunities and challenges, as illustrated by the discussion of Nigeria in Box 6 below.

\section{Box 6: Commentary on long-term growth projections for Nigeria}

Over the past decade, Nigeria has boasted superior economic growth ${ }^{26}$ and, with the right reforms and investments, Nigeria could become one of the world's leading economies by 2030 , with further progress by 2050. Nigeria's potential advantages for future growth include a large consumer market, a strategic geographic location, and a young and highly entrepreneurial population.

In April 2014, the Nigerian National Bureau of Statistics released the numbers for Nigeria's GDP rebasing, which had not been conducted since 1990. Since the previous study, it is estimated that the Nigerian economy has grown by $90 \%$, with a national GDP of around US $\$ 510$ billion in 2013. This makes Nigeria Africa's largest economy, overtaking South Africa, and the $20^{\text {th }}$ largest economy in the world according to IMF estimates for 2014 .

According to our long term projections, Nigeria could sustain average growth of around 5-6\% per annum in the long run, following projected growth of around 6-7\% in the rest of this decade, assuming broadly growthfriendly policies are pursued. While foreign investment has in absolute terms long been focused on the oil sector, portfolios are becoming increasingly diversified, moving towards the power, agriculture and mining areas of the economy that have demonstrated a comparative advantage in emerging markets vis-à-vis the West.

The World Bank's 2014 'Doing business in Nigeria' report recorded 34 significant improvements in the ease of doing business since 2010. The Federal Government's focus on infrastructure development (e.g. power, roads, and rail) is expected to support further growth of the economy. Other transformation programs include power sector reform and the Pension Reform Act 2014.

There is clear upside potential for five major sectors of the Nigerian economy:

- Retail and wholesale trade. Based on an expanding consumer class in Nigeria, retail and wholesale spending could rise strongly over the next few decades. This could make this the largest sector of the economy in the longer term and provides a particularly good opportunity for producers of fast-moving consumer items such as juices, which could grow by more than 10\% per year up to 2030.

- Agriculture. The sector, which is now the largest at 22\% of GDP, could more than double in size by 2030. This would require raising yields through greater use of fertilizer, seeds, and mechanized implements, shifting the crop mix to more valuable crops and increasing the amount of land under cultivation.

- Infrastructure. On average, the value of a nation's core infrastructure-roads, railways, ports, airports, the electrical system-is about $70 \%$ of GDP; in Nigeria, core infrastructure is estimated to be only around $35 \%-40 \%$ of GDP. Its road network lags well behind other emerging economies such as China and even India. On a per capita basis, Nigeria has one-third the residential buildings of Indonesia and one-sixth of the commercial space. Between core infrastructure and real estate, total infrastructure investments in Nigeria could be as high as US\$1.5trillion between 2014 and 2030.

\footnotetext{
${ }^{26}$ World Bank: Ease of Doing Business Report, 2014
} 
- Manufacturing. Manufacturing in Nigeria remains at a relatively early stage of development, contributing only around $7 \%$ of GDP in 2013. It has, however, achieved strong growth recently, with output rising by $13 \%$ per year from 2010 to 2013. Based on current trends, this could yield a four-fold increase in manufacturing output by 2030.

- Oil and gas. While the oil and gas sector is expected to grow relatively modestly compared to other sectors, and remains vulnerable to global price fluctuations as seen recently, its success is still important for the Nigerian economy. With the right reforms, liquids production could increase from $2.35 \mathrm{~m}$ barrels a day on average now to over $3 \mathrm{~m}$ barrels a day by 2030, while natural gas output could grow at around $6 \%$ per annum to 2030.

In recent months, the price of crude oil has fallen very sharply. With Nigeria producing about 2.4 million barrels per day and exporting 2.2 million barrels per day, the country may have lost as much as $\$ 11.5$ billion $^{27}$ between June and November this year, forcing the federal government to introduce a raft of measures to shore up its revenue in the face of dwindling earning from crude oil, its main revenue source. The situation could become worse in the short term as oil price falls have continued.

It should, however, be noted that this is not an entirely new experience as the country has been through a similar situation in 2008 when oil prices fell sharply to below $\$ 40$ per barrel (though in that case it rebounded relatively quickly, which may not happen this time). The country and the economy could ultimately benefit from a drop in oil prices if it provides an incentive for greater economic diversification.

Overall, Nigeria continues to be an attractive place to invest not because it is an oil producer, but because of the immense size of its domestic market and the extraordinary commercial energy of its people, which remains largely untapped.

Andrew S. Nevin, Partner, PwC Nigeria, andrew.x.nevin@ng.pwc.com

\subsection{Implications for business strategy}

Our analysis has a number of high level messages for businesses considering how to develop their global strategies, although all of these would need careful tailoring to individual circumstances.

First, it will be difficult to sustain the growth rates of the 2000 to 2012 period in the E7, and indeed other emerging markets, given the combination of economic bottlenecks and institutional deficiencies. This is backed up by the earlier analysis in this report. Managers need to understand the political, legal and regulatory risks and have procedures in place to avoid or at least mitigate them as they arise.

Our Growth Markets Centre ${ }^{28}$ has developed a systematic framework (see Figure 17) to deal with these and other strategic issues arising, covering four key areas:

- Business environment

- Value proposition

- Financial and human capital

- $\quad$ Operating model.

\footnotetext{
${ }_{27}$ ThisDay Live: Nigeria Loses $\$ 11.5$ bn to Tumbling Oil Prices, December 2014

${ }^{28}$ For more details see our Growth Markets Centre website at: http://www.pwc.com/gx/en/growth-markets-centre/index.jhtml
} 
Figure 17: PwC Growth Markets Assessment Framework

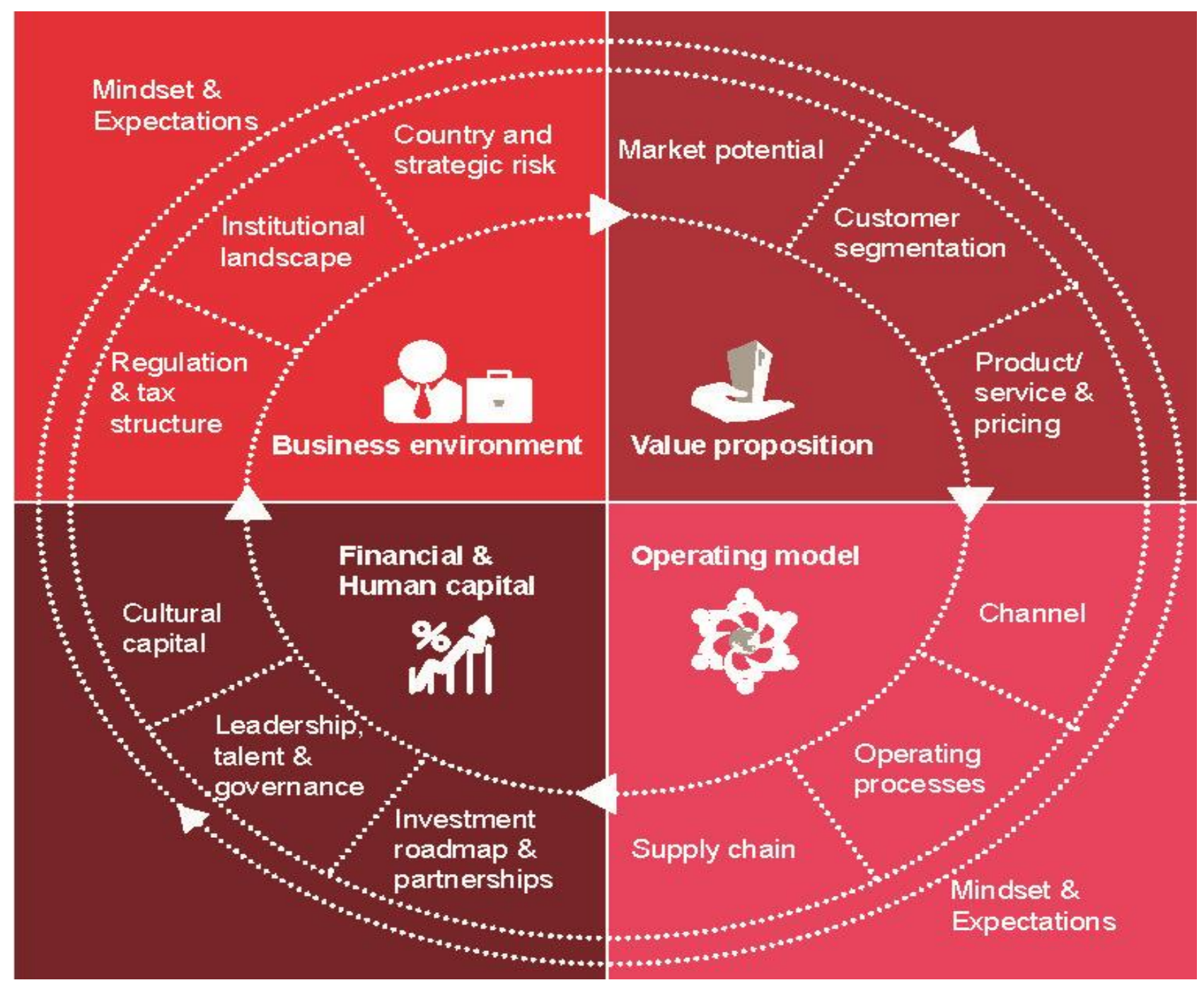

Source: PwC

Second, emerging markets vary greatly in their institutional strengths and weaknesses and need to be assessed in a nuanced way. There could also be major differences in institutional strengths between industry sectors within countries. Deep local knowledge that is updated in real time is critical here to manage businesses successfully in an emerging market environment. Having the right local partners to navigate you through local political, legal and regulatory systems is also critical ${ }^{29}$. Identifying and promoting local talent who understand local business and social cultures better than any outsider will also be an increasing source of comparative advantage.

It will also be important to understand customer dynamics as these markets become more mature and sophisticated, with increasing use of digital technologies (e.g. China has the largest number of internet users in the world today - tomorrow it could be India) ${ }^{30}$.

\footnotetext{
${ }^{29}$ As discussed further in a recent PwC Growth Markets Centre report 'Presence to Profitability': http://www.pwc.com/gx/en/growthmarkets-centre/presence-to-profitability.jhtml

${ }^{30}$ For more details of how technological breakthroughs are driving market dynamics, see our megatrends website at: http://www.pwc.co.uk/issues/megatrends/issues/technological-breakthroughs.jhtml
} 
Third, for larger Western companies making strategic investments in emerging markets, part of their contribution could be to try to improve the local institutional framework. This could involve offering appropriate technical assistance and advice to local governments in areas like corporate governance, fiscal policy and intellectual property rights protection. It could also involve investing in social and economic infrastructure (e.g. schools, roads, railways, power and water networks) where these are critical to a company's longer term success in a region.

Fourth, don't forget existing core markets in North America and Europe. These will remain very significant players in the global economy for decades to come. Their average income levels will remain much higher than in even the best-performing emerging markets for the foreseeable future. And they will, generally speaking, still be easier and lower risk places to do business given their political and institutional strengths, even though we project their growth rates to be relatively slow.

Finally, marketing strategies will also need to adjust to the latest economic and technological trends, as argued by Adam Smith of GroupM in the interview in Box 7 below.

Box 7: 'World in 2050': Interview with Adam Smith, Futures Director, GroupM

\section{Were there any major surprises in the projected GDP growth rates?}

No. I did, however, form an impression of institutional bias that all will find the path to Washington Consensus righteousness. I find it hard to be optimistic about Egypt, Argentina, Iran and Russia (or indeed Venezuela, which is missing from the study).

\section{What would you see as the key risks to achieving these projected growth rates?}

There are downside risks associated with shrinking workforces in some countries and/or productivity being impaired by: 1) the rising average age of workforces; 2) insufficient competition in, or resource allocation to, or staff incentives in, education; 3) diversion of capital into financing old-age consumption rather than capital investment; 4) reluctance in western politics to roll back employment protection; and 5) rising inequality impeding growth in aggregate demand.

Upside risks include falling dependence on primary resources (e.g. oil) leading to a higher intangible element in wealth creation and a lower reliance on tradeables, which could reduce the scope for mercantilism. This should help to rebalance present global trade imbalances between surplus and deficit nations and tend to boost aggregate demand.

However, a higher element of services in consumer economies also increases reliance on domestic efficiency (where the US is well-placed, but Germany, China and Russia less so). I wonder what international stabilisers or mechanisms exist to equalise relative domestic advantage and disadvantage: perhaps trade agreements, regulation and standardisation? These might not, however, have the power of market remedies. Perhaps we will see a second wave of offshoring the provision of services, or offshoring parts of the value chain, or immigration. Take a haircut, for example. The haircut must be provided domestically and on demand, but the staff can be imported through immigration.

A world of lower tradeables will reduce domestic competition for labour (between tradeable and non-tradeable employers) and so suppress wage inflation. More immigration will tend to do the same, as will decelerating productivity gains.

As emerging giants like China move more towards being consumption-led economies and digital technology become increasingly widespread, what are the implications for consumer and media sector businesses?

Satisfying consumer demand becomes more intangible and 'experimental' as discretionary spending power rises and the volume of services rises relative to goods. This requires more marketing effort, and probably increased marketing costs relative to sales, whether in paid media or management time, or calls on creative talent. Digitisation places more options in marketer hands. More options will I think stimulate more expense and higher risk. So entry barriers will rise and the middle ground will shrink in the classic way - 'get big, get specialised, or get out'. The potential for digital communication appears infinite: water, water, everywhere. 'Share of mind' is, however, strictly limited and will only grow scarcer as ad-avoidance becomes cheaper and easier. 


\section{What are the key things that businesses should consider in their advertising and marketing strategy in the medium to long term to reflect these global trends?}

Advertising and marketing generally comprises successive short terms, rather than fixed longer term strategies. To the extent, however, that a longer term view is taken, the 'key things' might include:

1. Demography, wealth and spending power. For example, marketing to the old is generally not done very well. A common mistake is to portray the target audience in the advertising, when the target audience does not want a mirror.

2. Brand portfolio management, bearing in mind the 'get big' saying above. Some owners will dispose of some of their brands, some acquire. Brands rarely die sudden deaths.

3. Brand extension to turn products into services, and to simplify marketing (or at least mitigate growing complication).

4. Reconciling 'addressability at scale' with the proven scale economies of broadcast 'messaging'. I think this is essentially a technological problem: using data (preferably one's own, not bought or shared) to aggregate large numbers of the most likely prospects.

5. Brand advertising is not direct marketing. Brand advertising is more sensitive to context and risk, and its results are intangible and thus harder to measure. Brands should learn the disciplines and techniques of direct marketing, but not become it. In a world driven by data and an algorithm for everything it's worth remembering that humans love new things and they love serendipity and browsing. This is also why they are disloyal and forgetful, and why marketing must be broad, persistent, and distinctive. As a consequence, marketing as we know it will persist, but it will need to clear ever-higher hurdles of relevance and engagement.

In summary, while emerging markets have considerable growth potential as our analysis in this report shows, they can also be an institutional minefield - both managers and investors need to tread carefully. Global strategies need to strike the right balance between mature, lower risk advanced economies and faster-growing but generally higher risk emerging markets. The correct balance will vary from company to company, but our Growth Markets Strategy toolkit can help guide the way. 
Appendices 


\section{Appendix A: Drivers of growth}

\section{A.1 Model structure}

In line with established economic theory and a large number of previous research studies, we adopt a simplified model of long-term economic growth ${ }^{31}$ in which the shares of national income going to capital and labour are assumed to be constant ${ }^{32}$. GDP growth in this model is driven by assumptions on three factors, which we discuss in turn below:

- Growth in the physical capital stock, which is determined by new capital investment less depreciation of the existing capital stock;

- Growth in the quality of labour ('human capital'), which is assumed to be related to current and projected average education levels in the workforce; and

- Technological progress, which drives improvements in total factor productivity (TFP).

In addition, as noted above, the model also makes assumptions about future trends in real market exchange rates relative to PPP rates.

In applying this approach we take the US as our benchmark economy, as this is assumed to be at the 'global frontier' in terms of technology and so productivity. US GDP growth is modelled in a somewhat simpler manner based on assumed labour productivity growth of $2 \%$ per annum and UN working age population projections. As described further below, other countries are then assumed to catch up gradually with US productivity levels over time (at rates that vary by country depending on their circumstances).

One limitation of our model that is worth noting up front is that, although it does allow for linkages between country performance due to shifts in the global technological frontier, it does not allow for performance in one country (except the US) to affect performance in other countries directly. Capturing these inter-linkages would require a much more complex modelling approach covering trade and investment flows between countries. Our approach limits the value of the model for global simulation purposes, but is much more tractable for the purposes of producing long-term growth projections for individual countries. Furthermore, our assumptions are chosen in a manner that is intended to be broadly consistent across countries, so that they constitute a plausible 'main scenario' for the world economy as a whole.

\section{A.1.1. Demographics}

We use the latest UN projections for the population aged 15-59 as a proxy for labour force growth (these include net migration). Some economies might be able to achieve faster growth here if they can raise their employment rates, but any such effects are difficult to predict and we have therefore not included them in our base case estimates.

All of the countries considered in this study, with the exception of India, are projected by the UN to see a declining share of their total populations in the prime 15-59 working age group between 2014 and 2050. This is the counterpart of the fact that all 24 countries (including India) are projected to see a rising share of their populations aged 60 or over. Korea, Spain, Russia, Japan, Italy and China are expected to see the largest declines in the share of the prime working age group over the period to 2050. Significant ageing effects are

\footnotetext{
${ }^{31}$ The model goes back to the Nobel Prize-winning work of Solow $(1956,1957)$, which has remained the standard academic approach ever since the late 1950 and was later applied empirically by Denison (1985) and many others. A well-known more recent example of a research study on this topic is D. Wilson and R.Purushothaman, 'Dreaming With BRICs: The Path to 2050', Goldman Sachs, Global Economics Paper No:99, October 2003. This applies a similar growth modelling approach to four leading emerging market economies, except that it does not explicitly include human capital in its calculations. Given the importance of this factor, we prefer to make our assumptions on this variable explicit, as in many earlier academic studies (e.g. Hall and Jones (1998) and Barro and Lee (2001)).

${ }^{32}$ More formally, we assume a Cobb-Douglas production function with constant returns to scale.
} 
therefore by no means confined to the existing developed countries, but are also important for some of the major emerging market economies.

If we look instead at expected growth in prime working age populations (see Figure A1), then there are more countries with positive growth rates due either to relatively high birth rates (e.g. Nigeria, Philippines, India) and/or immigration rates (e.g. the US). But all of the OECD countries in Europe are facing declining working age populations, except the UK and France where they are projected to be broadly static. This is also true of Japan, South Korea, Thailand, China and Russia. The impact of a declining, ageing population is particularly significant in restricting Russia's ability to increase its share of world GDP in a similar way to other large emerging economies. An ageing population also acts as a drag on Chinese growth in the longer term relative to that of India.

Figure A-1: UN estimates of average working age population growth to 2050 (\% p.a.)

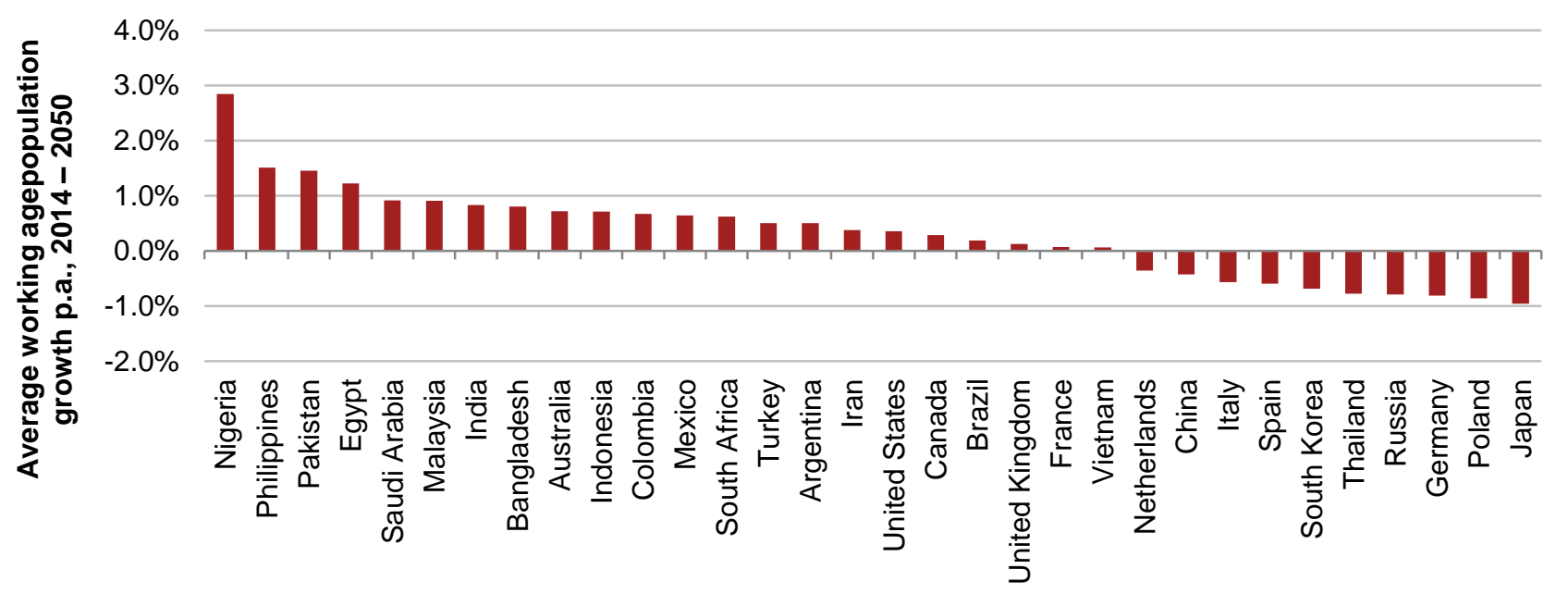

Source: United Nations

\section{A.1.2 Education}

In common with several past academic studies, we have based our estimates of the human capital stock on the data on average years of schooling for the population aged 25 and over from Barro and Lee (2001). We then follow the approach of Hall and Jones (1998), which in turn was based on the survey of international estimates of the returns to schooling in countries at different levels of economic development by Psacharopoulus (1994). Specifically, for the first four years of education, we assume a rate of return of $13.4 \%$, corresponding to average estimates for sub-Saharan Africa. For the next four years, we assume a return of $10.1 \%$, corresponding to the average for the world as a whole. For education beyond the $8^{\text {th }}$ year, we assume estimated OECD average returns of $6.8 \%$. This approach leads to estimates of the stock of human capital per worker as an index relative to the US.

We then assume that the average years of schooling of the over-25 population rises over time in each country at rates derived by extrapolating forward from trends over the past 5-20 years (the weight given to past averages over 5,10 or 20 years varies across countries depending on what we consider to be the best indicator of underlying trends in education levels in each country). In line with trends over this past period, average years of schooling are assumed to rise at the slowest rate in the US, reflecting their higher starting point. This allows other countries to catch up with estimated average US levels of human capital per worker.

The fastest educational catch-up rates are assumed to be seen in Asian countries such as India and Indonesia, which is consistent with trends in recent periods and is an important factor in their relatively strong projected growth performance. Russia and Poland, with relatively high initial average education levels, make some further progress but have less scope for rapid catch-up in this area. 


\section{A.1.3. Capital investment}

We began with estimates from King and Levine (1994) of capital stock to output ratios in the mid-1980s. These ratios are projected forward to our 2014 base year using data on investment as a \% of GDP from the Penn World Tables (v. 6.1) database up to 2000, supplemented by IMF data for more recent years. We assume a uniform $5 \%$ annual depreciation rate of the existing capital stock both in this calculation and in the forward-looking projections, which is consistent with the 4-6\% depreciation rates generally assumed in the academic literature. The resulting capital-output ratios in 2014 vary from around 1 in Nigeria to 4.2 in Japan (the UK ratio is around 2.5).

Table A-1: Investment rate assumptions

\begin{tabular}{|c|c|c|}
\hline \multicolumn{3}{|c|}{ Investment as $\%$ GDP } \\
\hline Country & Initial rate (2014) & From 2025 \\
\hline Australia & $26.4 \%$ & $22.4 \%$ \\
\hline Canada & $21.4 \%$ & $16.4 \%$ \\
\hline France & $19.1 \%$ & $15.1 \%$ \\
\hline Germany & $20.1 \%$ & $18.1 \%$ \\
\hline Italy & $20.3 \%$ & $18.3 \%$ \\
\hline Japan & $24.8 \%$ & $19.8 \%$ \\
\hline South Korea & $30.9 \%$ & $23.9 \%$ \\
\hline Spain & $23.9 \%$ & $18.9 \%$ \\
\hline United Kingdom & $17.2 \%$ & $16.0 \%$ \\
\hline United States & $20.6 \%$ & $16.0 \%$ \\
\hline Brazil & $18.4 \%$ & $18.4 \%$ \\
\hline China & $36.3 \%$ & $20.3 \%$ \\
\hline India & $25.7 \%$ & $23.7 \%$ \\
\hline Indonesia & $26.0 \%$ & $23.0 \%$ \\
\hline Mexico & $19.8 \%$ & $19.8 \%$ \\
\hline Russia & $17.9 \%$ & $17.9 \%$ \\
\hline Turkey & $21.2 \%$ & $21.2 \%$ \\
\hline Argentina & $16.4 \%$ & $17.4 \%$ \\
\hline Bangladesh & $21.2 \%$ & $23.2 \%$ \\
\hline Colombia & $19.2 \%$ & $19.2 \%$ \\
\hline Egypt & $15.5 \%$ & $18.0 \%$ \\
\hline Iran & $20.5 \%$ & $9.5 \%$ \\
\hline Malaysia & $28.2 \%$ & $28.2 \%$ \\
\hline Netherlands & $20.6 \%$ & $20.6 \%$ \\
\hline Nigeria & $5.8 \%$ & $8.0 \%$ \\
\hline Pakistan & $16.2 \%$ & $17.2 \%$ \\
\hline Philippines & $20.5 \%$ & $25.5 \%$ \\
\hline Poland & $20.0 \%$ & $20.0 \%$ \\
\hline Saudi Arabia & $20.5 \%$ & $24.5 \%$ \\
\hline South Africa & $17.8 \%$ & $23.8 \%$ \\
\hline
\end{tabular}




\begin{tabular}{lcc}
\hline Country & Initial rate (2014) & From 2025 \\
Thailand & $29.8 \%$ & $29.8 \%$ \\
\hline Vietnam & $20.1 \%$ & $25.1 \%$ \\
\hline
\end{tabular}

Note: Investment rates assumed to adjust smoothly between 2014 and 2025 to long run level shown in final column above.

Source: PwC assumptions informed by historic data from IMF

Looking forward, we assume that initial average annual investment/GDP ratios, which vary from around 6\% in Nigeria to around $36 \%$ in China, adjust gradually to long run investment levels after 2025 that vary more narrowly from $8 \%$ in Nigeria to around $25-30 \%$ in some Asian emerging economies (see Table A1 above).

These assumptions reflect the view that, with declining marginal returns on new investment over time, the very high investment/GDP ratios seen in China and other Asian emerging markets will tend to decline in the long run as these economies mature (as has happened with Japan since the early 1990s).

In line with similar past studies, we assume for simplicity that capital has a constant $1 / 3$ share in national output, with labour having a 2/3 share. While labour shares have declined in many advanced economies in recent years, it is not at all clear if this will continue in the long run, so we prefer to make this simpler assumption to avoid over-complicating the model.

\section{A.1.4. Technological progress}

This factor is assumed to be related to the extent to which a country lags behind the technological leader (assumed here to be the US) and so has the potential for 'catch-up' through technology transfer, conditional upon levels of physical and human capital investment (as set out above) and other more institutional factors such as political stability, openness to trade and foreign investment, the strength of the rule of law, the strength of the financial system and cultural attitudes to entrepreneurship. These latter institutional factors are not readily quantifiable through a single index, but are reflected in our assumptions on the relative speed of technological catch-up in each country. 
In some cases (e.g. India, Indonesia and Brazil), we assume a slower rate of technological progress in the short term, but assume the pace of catch-up accelerates in the longer term as these countries strengthen their institutional frameworks. In the longer term, the rate of catch-up is assumed to converge to an annual rate of $1.5 \%$ of the total factor productivity gap with the US, which is in line with the results of past academic research 33 suggesting typical long-term catch-up rates of around 1-2\% per annum.

It is important to stress that this approach is only intended to produce projections for long-term trend growth. It ignores cyclical fluctuations around this long-term trend, which history suggests could be significant in the short term for emerging economies in particular, but which we cannot hope to predict more than a year or two ahead at most. It also ignores the possibility of major adverse shocks (e.g. political revolutions, natural disasters or military conflicts) that could throw countries off their equilibrium growth paths for longer periods of time, but which are inherently impossible to predict. At the same time, our modelling ignores the possibility of a sudden leap forward in the technological frontier (here represented by US labour productivity growth, which as noted above we assume to increase at a steady $2 \%$ per annum rate in real terms, reflecting recent historic trends) due to some major new wave of innovation either from new breakthrough discoveries not imagined yet, or innovative application of existing technologies.

\section{A.2. Real exchange rates: PPPs vs. MERs}

GDP at PPPs is a better indicator of average living standards or volumes of outputs or inputs, because it corrects for price differences across countries at different levels of development. In general, price levels are significantly lower in emerging economies so looking at GDP at PPPs narrows the income gap with the advanced economies compared to using market exchange rates.

However, GDP at MERs is a better measure of the relative size of the economies from a business perspective, at least in the short term. For long run business planning or investment appraisal purposes, it is crucial to factor in the likely rise in real market exchange rates in emerging economies towards their PPP rates. This could occur either through relatively higher domestic price inflation in these emerging economies, or through nominal exchange rate appreciation, or (most likely) some combination of both of these effects.

When estimating GDP at market exchange rates in 2050, a similar methodology is therefore adopted as in the original 'World in 2050' report where market exchange rates are converging to PPP rates with different converging factors depending on the type of economy. This leads to projections of significant rises in real market exchange rates for the major emerging market economies due to their higher productivity growth rates, although these projected MERs still fall some way below PPP levels in 2050 for the least developed emerging markets. We have, however, updated our methodology here with new econometric estimates of how this emerging market real exchange rate appreciation is related to relative productivity growth.

For the advanced economies, we assume that real exchange rates converge very gradually to their PPP rates at a steady pace over the period from 2015 to 2050 . This is consistent with academic research showing that purchasing power parity does hold in the long run, at least approximately, but not in the short run.

In Appendix B below, we look in more detail at our results for GDP at MERs, which make use of these assumptions on real exchange rate movements over time.

${ }^{33}$ As summarised, for example, in Chapter 6 of Macroeconomics and the global business environment by David Miles and Andrew Scott (John Wiley \& Sons, 2004). 


\section{Appendix B: Additional projections for GDP at market exchange rates}

Table B1 shows the summary of GDP projections for 2014, 2030 and 2050 measured at market exchange rates (MERs). Most of the findings and observations from Table 1 (rankings based on GDP at PPPs) in the main text continue to hold: China overtakes the US as the largest economy in the world while India moves into clear third place, well ahead of Indonesia and Brazil in fourth place by 2050. Indonesia, Mexico and Nigeria take their place within the top 10 rankings by 2050.

Table B-1: GDP at MER rankings

\begin{tabular}{|c|c|c|c|c|c|c|}
\hline & \multicolumn{2}{|c|}{2014} & \multicolumn{2}{|c|}{2030} & \multicolumn{2}{|c|}{2050} \\
\hline $\begin{array}{l}\text { PPP } \\
\text { rank }\end{array}$ & Country & $\begin{array}{c}\text { GDP at MER } \\
\text { (2014 US\$bn) }\end{array}$ & Country & $\begin{array}{c}\text { Projected GDP } \\
\text { at MER (2014 } \\
\text { US\$bn) }\end{array}$ & Country & $\begin{array}{c}\text { Projected GDP } \\
\text { at MER (2014 } \\
\text { US\$bn) }\end{array}$ \\
\hline 1 & United States & 17,416 & China & 26,667 & China & 53,553 \\
\hline 2 & China & 10,355 & United States & 25,451 & United States & 41,384 \\
\hline 3 & Japan & 4,770 & India & 7,304 & India & 27,937 \\
\hline 4 & Germany & 3,820 & Japan & 5,994 & Indonesia & 8,742 \\
\hline 5 & France & 2,902 & Germany & 4,734 & Brazil & 8,534 \\
\hline 6 & United Kingdom & 2,848 & Brazil & 4,065 & Japan & 7,914 \\
\hline 7 & Brazil & 2,244 & United Kingdom & 3,908 & Mexico & 7,087 \\
\hline 8 & Italy & 2,129 & France & 3,663 & Russia & 6,610 \\
\hline 9 & Russia & 2,057 & Russia & 3,323 & Nigeria & 6,354 \\
\hline 10 & India & 2,048 & Mexico & 2,881 & Germany & 6,338 \\
\hline 11 & Canada & 1,794 & Indonesia & 2,660 & United Kingdom & 5,744 \\
\hline 12 & Australia & 1,483 & Italy & 2,638 & France & 5,207 \\
\hline 13 & South Korea & 1,449 & South Korea & 2,557 & Saudi Arabia & 4,481 \\
\hline 14 & Spain & 1,400 & Canada & 2,391 & Turkey & 4,354 \\
\hline 15 & Mexico & 1,296 & Spain & 2,077 & South Korea & 4,142 \\
\hline 16 & Netherlands & 880 & Saudi Arabia & 2,048 & Italy & 3,617 \\
\hline 17 & Indonesia & 856 & Australia & 2,009 & Canada & 3,583 \\
\hline 18 & Turkey & 813 & Turkey & 1,822 & Spain & 3,099 \\
\hline 19 & Saudi Arabia & 778 & Nigeria & 1,756 & Australia & 2,903 \\
\hline 20 & Nigeria & 594 & Poland & 1,161 & Egypt & 2,896 \\
\hline 21 & Poland & 552 & Netherlands & 1,128 & Philippines & 2,747 \\
\hline 22 & Argentina & 536 & Thailand & 990 & Pakistan & 2,727 \\
\hline 23 & Iran & 403 & Malaysia & 930 & Malaysia & 2,676 \\
\hline 24 & Colombia & 400 & Argentina & 926 & Thailand & 2,658 \\
\hline 25 & Thailand & 380 & Colombia & 922 & Vietnam & 2,555 \\
\hline 26 & South Africa & 341 & Philippines & 848 & South Africa & 2,521 \\
\hline
\end{tabular}




\begin{tabular}{|c|c|c|c|c|c|c|}
\hline \multirow[b]{2}{*}{$\begin{array}{l}\text { PPP } \\
\text { rank }\end{array}$} & \multicolumn{2}{|c|}{2014} & \multicolumn{2}{|c|}{2030} & \multicolumn{2}{|c|}{2050} \\
\hline & Country & $\begin{array}{c}\text { GDP at MER } \\
\text { (2014 US\$bn) }\end{array}$ & Country & $\begin{array}{c}\text { Projected GDP } \\
\text { at MER (2014 } \\
\text { US\$bn) }\end{array}$ & Country & $\begin{array}{c}\text { Projected GDP } \\
\text { at MER (2014 } \\
\text { US\$bn) }\end{array}$ \\
\hline 27 & Malaysia & 337 & Iran & 848 & Colombia & 2,485 \\
\hline 28 & Philippines & 290 & Egypt & 806 & Bangladesh & 2,450 \\
\hline 29 & Egypt & 285 & South Africa & 767 & Poland & 2,422 \\
\hline 30 & Pakistan & 233 & Pakistan & 729 & Iran & 2,243 \\
\hline 31 & Vietnam & 188 & Vietnam & 685 & Argentina & 2,142 \\
\hline 32 & Bangladesh & 187 & Bangladesh & 639 & Netherlands & 1,581 \\
\hline
\end{tabular}

Source: IMF estimates for 2014 (from October 2014 WEO database), PwC projections for 2030 and 2050

Table B2 shows the annual average growth rates measured in MERs for each country from the period to 2050. It is similar to Table 2 in the main text, but it also shows the additional contribution of projected real exchange rate movements to the average growth rates measured in constant US dollar terms. Table B-2 shows that:

- The projected exchange rate movements from our model give a further boost to growth in dollar terms for the emerging economies. This is especially true for countries such as Vietnam and Indonesia, as the real appreciation projected to be experienced by their currencies is enough to push them ahead of Nigeria to become the two fastest growing economies for the next few decades.

- On the other hand, some of the developed economies such as the UK, Australia, and Germany are projected to experience very gradual real currency depreciation against the US dollar as their market exchange rates are currently above PPP rates. This contributes negatively to their growth when measured in MERs as compared to the PPP projections.

Table B-2: Breakdown of components of average real growth in GDP at MERs (2014 - 2050)

\begin{tabular}{lc|ccc}
\hline Country & $\begin{array}{c}\text { Average population } \\
\text { growth p.a } \%\end{array}$ & $\begin{array}{c}\text { Average real growth } \\
\text { per capita p.a } \%\end{array}$ & $\begin{array}{c}\% \text { change due to real } \\
\text { MER changes }\end{array}$ & $\begin{array}{c}\text { Average real GDP growth } \\
\text { p.a. (in USD at MERs) }\end{array}$ \\
\hline Vietnam & $0.3 \%$ & $5.0 \%$ & $2.1 \%$ & $7.4 \%$ \\
\hline India & $0.7 \%$ & $4.1 \%$ & $2.5 \%$ & $7.3 \%$ \\
\hline Bangladesh & $0.7 \%$ & $4.4 \%$ & $2.2 \%$ & $7.3 \%$ \\
\hline Pakistan & $1.1 \%$ & $3.3 \%$ & $2.6 \%$ & $6.9 \%$ \\
\hline Egypt & $1.1 \%$ & $3.1 \%$ & $2.4 \%$ & $6.6 \%$ \\
\hline Nigeria & $2.5 \%$ & $2.8 \%$ & $1.3 \%$ & $6.6 \%$ \\
\hline Philippines & $1.3 \%$ & $3.2 \%$ & $1.8 \%$ & $6.3 \%$ \\
\hline Malaysia & $0.9 \%$ & $3.6 \%$ & $1.7 \%$ & $6.2 \%$ \\
\hline South Africa & $0.5 \%$ & $3.8 \%$ & $1.5 \%$ & $5.8 \%$ \\
\hline Thailand & $-0.2 \%$ & $4.0 \%$ & $2.0 \%$ & $5.7 \%$ \\
\hline Indonesia & $0.7 \%$ & $2.8 \%$ & $2.2 \%$ & $5.7 \%$ \\
\hline Colombia & $0.7 \%$ & $3.5 \%$ & $1.0 \%$ & $5.3 \%$ \\
\hline Iran & $0.7 \%$ & $2.0 \%$ & $2.3 \%$ & $5.0 \%$ \\
\hline Saudi Arabia & $0.9 \%$ & $2.4 \%$ & $1.6 \%$ & $4.9 \%$ \\
\hline Mexico & $0.6 \%$ & $3.0 \%$ & $1.1 \%$ & $4.7 \%$ \\
\hline Turkey & $0.6 \%$ & $2.7 \%$ & $1.3 \%$ & $4.7 \%$ \\
\hline China & $3.4 \%$ & $1.2 \%$ & $4.6 \%$ \\
\hline
\end{tabular}




\begin{tabular}{lc|ccc}
\hline Country & $\begin{array}{c}\text { Average population } \\
\text { growth p.a } \%\end{array}$ & $\begin{array}{c}\text { Average real growth } \\
\text { per capita p.a } \%\end{array}$ & $\begin{array}{c}\% \text { change due to real } \\
\text { MER changes }\end{array}$ & $\begin{array}{c}\text { Average real GDP growth } \\
\text { p.a. (in USD at MERs) }\end{array}$ \\
\hline Poland & $-0.3 \%$ & $3.0 \%$ & $1.5 \%$ & $4.3 \%$ \\
\hline Brazil & $0.4 \%$ & $3.0 \%$ & $0.7 \%$ & $4.1 \%$ \\
\hline Argentina & $0.6 \%$ & $2.1 \%$ & $1.2 \%$ & $3.9 \%$ \\
\hline Russia & $-0.5 \%$ & $2.7 \%$ & $1.2 \%$ & $3.4 \%$ \\
\hline South Korea & $0.1 \%$ & $2.4 \%$ & $0.6 \%$ & $3.0 \%$ \\
\hline Spain & $0.1 \%$ & $2.2 \%$ & $0.3 \%$ & $2.5 \%$ \\
\hline United States & $0.6 \%$ & $1.8 \%$ & $0.0 \%$ & $2.4 \%$ \\
\hline Canada & $0.7 \%$ & $1.8 \%$ & $-0.4 \%$ & $2.1 \%$ \\
\hline France & $0.3 \%$ & $2.0 \%$ & $-0.3 \%$ & $2.1 \%$ \\
\hline Japan & $-0.5 \%$ & $2.4 \%$ & $0.0 \%$ & $2.0 \%$ \\
\hline United Kingdom & $0.4 \%$ & $2.0 \%$ & $-0.4 \%$ & $2.0 \%$ \\
\hline Germany & $-0.4 \%$ & $2.4 \%$ & $-0.2 \%$ & $1.9 \%$ \\
\hline Australia & $1.0 \%$ & $1.6 \%$ & $-0.8 \%$ & $1.7 \%$ \\
\hline Netherlands & $0.0 \%$ & $1.9 \%$ & $-0.2 \%$ & $1.7 \%$ \\
\hline Italy & $-0.1 \%$ & $1.8 \%$ & $-0.1 \%$ & $1.7 \%$ \\
\hline
\end{tabular}

Source: PwC analysis 


\section{Authors, contacts and services}

This report was written by John Hawksworth and Danny Chan of PwC's Economics and Policy (E\&P) team in the UK with additional inputs from Andrew Nevin (PwC Nigeria), Gustavo Dreispiel (PwC Colombia), Patrick Tay (PwC Malaysia), and Mateusz Walewski (PwC Poland). Many other PwC economists from around our global network also contributed helpful comments or other inputs to the project, including Allan Zhang, David Wijeratne, Jeremy Thorpe, Tim Ogier, David Lancefield, Andrew Sentence, Robert Vaughan, Conor Lambe, Barret Kupelian. Simon Reed, Genevieve Lopes and Gill Carson provided excellent support on marketing and communications issues.

Special thanks are due to Richard Woolhouse (BBA), Rebecca Harding (Delta Economics), and Adam Smith (GroupM) for the contribution of their views and insights to our report.

For more information about this report please contact:

\begin{tabular}{ll}
\hline John Hawksworth & Danny Chan \\
Chief Economist & Senior Economist \\
T: $+44(0) 2072131650$ & T: + 44 (o)20 78043872 \\
E: john.hawksworth@uk.pwc.com & E: danny.chan@uk.pwc.com \\
\hline
\end{tabular}

\section{Economics and Policy (E\&P) services}

Our E\&P team's consulting services combine strategic analysis of macroeconomic and microeconomic trends with strong quantitative techniques across many sectors and areas of work including disputes and investigations, market reform, and foundations for growth. Further details of our services can be found on our website at:

http://www.pwc.co.uk/economics-policy/index.jhtml

Our E\&P team maintains in-house models of more than 25 leading economies which together account for over $80 \%$ of global GDP. For up-to-date projections please see our monthly Global Economy Watch report here:

http://www.pwc.co.uk/economic-services/global-economy-watch/index.jhtml

\section{Megatrends}

Further details of our megatrends research programme, which has been led by our E\&P team in the UK, can be found at:

http://www.pwc.co.uk/issues/megatrends/index.jhtml

This report focuses on the shift in global economic power, but is related to all five megatrends:

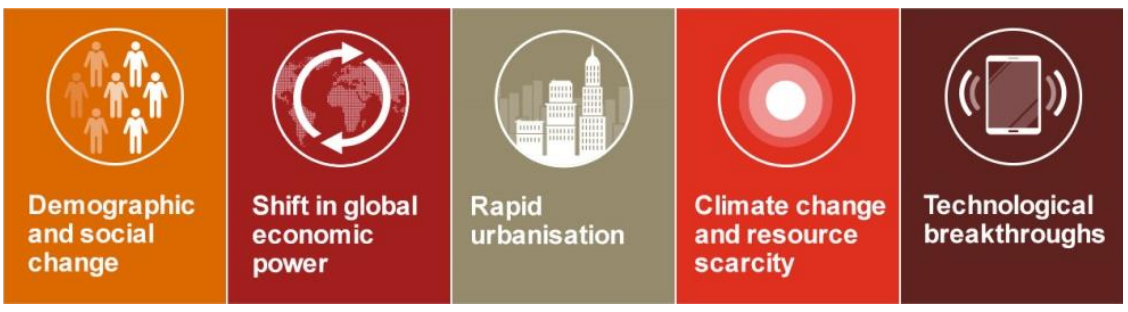




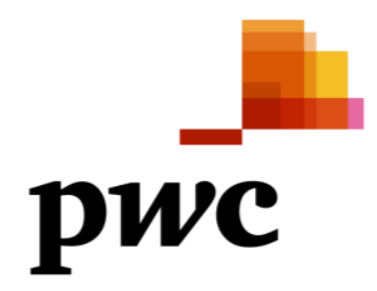

This publication has been prepared for general guidance on matters of interest only, and does not constitute professional advice. You should not act upon the information contained in this publication without obtaining specific professional advice. No representation or warranty (express or implied) is given as to the accuracy or completeness of the information contained in this publication, and, to the extent permitted by law, PricewaterhouseCoopers does not accept or assume any liability, responsibility or duty of care for any consequences of you or anyone else acting, or refraining to act, in reliance on the information contained in this publication or for any decision based on it. This publication (and any extract from it) must not be copied, redistributed or placed on any website, without PricewaterhouseCoopers' prior written consent.

(C) 2015 PricewaterhouseCoopers LLP. All rights reserved. In this document, "PwC" refers to the UK member firm, and may sometimes refer to the PwC network. Each member firm is a separate legal entity. Please see www.pwc.com/structure for further details.

150128-085441-DC-OS 